\title{
Evaluation of the Enhanced LEU Fuel (ELF) Design for Conversion of the Advanced Test Reactor to a Low-Enrichment Fuel Cycle
}

Mark D. DeHart, Zain Karriem, Michael A. Pope

August 2017

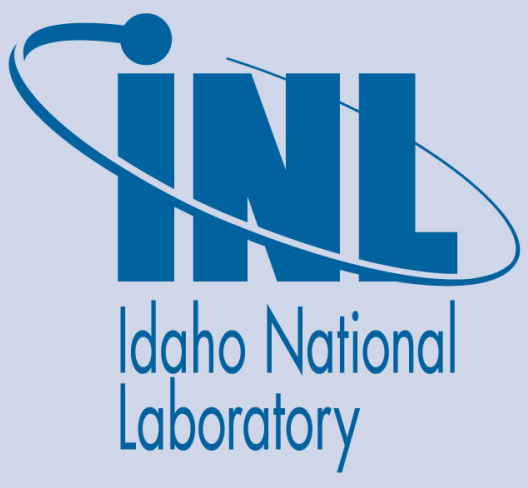

The INL is a U.S. Department of Energy National Laboratory operated by Battelle Energy Alliance 


\title{
Evaluation of the Enhanced LEU Fuel (ELF) Design for Conversion of the Advanced Test Reactor to a Low- Enrichment Fuel Cycle
}

\author{
Mark D. DeHart, Zain Karriem, Michael A. Pope
}

August 2017

Idaho National Laboratory Idaho Falls, Idaho 83415

http://www.inl.gov

Prepared for the

U.S. Department of Energy

Under DOE Idaho Operations Office

Contract DE-AC07-05ID14517 


\title{
Evaluation of the Enhanced LEU Fuel (ELF) Design for Conversion of the Advanced Test Reactor to a Low-Enrichment Fuel Cycle
}

\author{
Mark D. DeHart ${ }^{1 *}$, Zain Karriem ${ }^{1}$, Michael A. Pope ${ }^{2}$ \\ ${ }^{1}$ Reactor Physics Design and Analysis, Idaho National Laboratory, \\ ${ }^{2}$ Formerly of Idaho National Laboratory, \\ * Corresponding author: 2525 Fremont Avenue, Idaho Falls, ID, 83415, \\ Mark.DeHart@inl.gov
}

\begin{abstract}
A conceptual low-enrichment uranium (LEU) fuel design has been developed for the Advanced Test Reactor (ATR) at Idaho National Laboratory. The ATR is currently fueled with a high-enrichment fuel but is slated to be converted to LEU under programs led by the National Nuclear Security Administration of the U.S. Department of Energy. A conceptual LEU fuel design, the Enhanced LEU Fuel (ELF), has been developed assuming power peaking control through the use of variable fuel meat thicknesses and no use of burnable poison. In initial work, this design was shown to satisfy performance requirements for ATR operation. Following these design calculations, a safety analysis process was initiated to demonstrate that the ELF design would successfully meet safety limits for postulated accident conditions. Those calculations, performed using RELAP5 and ATR-SINDA, require physics analysis to provide spatial power distributions and kinetics parameters for various core operations configurations. This paper describes the findings of the physics analysis and provides predictions for the behavior of an LEU fueled version of ATR, and compares to calculations of the performance of the current HEU fuel.
\end{abstract}

Keywords: ATR, ATRC, HEU, LEU, Conversion, ELF 


\section{INTRODUCTION}

The Advanced Test Reactor (ATR), located at Idaho National Laboratory (INL), is one of only a few high-power research reactors of its general type in the world. Its capabilities support a variety of missions involving accelerated testing of nuclear fuel and other materials in a very high neutron flux environment, medical and industrial isotope production, and several other specialized applications. Along with its companion critical mockup, the ATR Critical Facility (ATRC), the ATR is one of the key nuclear engineering research and testing facilities within the US Department of Energy (DOE) National Laboratory Complex. The ATR and ATRC also serve as the centerpieces of the ATR National Scientific User Facility (NSUF), whose purpose is to facilitate the current trend toward broadening application of the ATR beyond its traditional base [1].

Under the current long-term DOE policy and planning scenario, both the ATR and the ATRC will be reconfigured at an appropriate time to operate with low-enrichment uranium (LEU) fuel. This will be accomplished under the auspices of the Office of Material Management and Minimization $\left(\mathrm{M}^{3}\right)$ within the National Nuclear Security Administration of the DOE. The primary objective of $\mathrm{M}^{3}$ is to achieve nuclear non-proliferation and threat reduction by minimizing and, when possible, eliminating weapons-usable nuclear material around the world. One of the goals of this mission is to convert all high-enrichment uranium (HEU) fueled reactors world-wide to LEU. Thus, the convert mission has defined specific objectives to complete the conversion of approximately 200 domestic and international civilian research reactors to use LEU fuels by 2030. Of these 200, 33 are in the U.S. All but five of the U.S. reactors have already been converted; the five remaining U.S. high performance research reactors (HPRRs) will require a new fuel type. These five reactors are part of a group of approximately 27 research reactors worldwide that cannot be converted using existing commercially available LEU fuels $[2,3,4]$.

The objective for the U.S. HPRR Program is to convert three U.S. Nuclear Regulatory Commission (NRC) licensed HPRRs by 2025: the MIT Nuclear Research Reactor (MITRR), the University of Missouri Research Reactor (MURR) and the National Institute of Standards and Technology Research Reactor (NBSR). Two DOE regulated test reactors (the High Flux Isotope Reactor, or HFIR, and the ATR, along with the ATRC critical facility will also converted, all by 2030. This conversion will require a new low enriched 
fuel to be qualified for use in these reactors, as well as the establishment of a capability to fabricate the qualified fuel. Based on extensive materials testing at INL and internationally, it was determined that only a high-density uranium-molybdenum (U-Mo) alloy would meet the performance requirements (e.g., maximum fission density, total number of fissions, etc.) of the five HPPRs [5]. The results of U-Mo testing in turn resulted in the selection of a monolithic U-Mo alloy containing $10 \%$ Mo by mass (U-10Mo) as the best fuel form to meet all HPPR needs. Furthermore, based on scoping irradiation test data, a fuel plate system composed of solid U-10Mo fuel meat with a $25.4 \mu \mathrm{m}$ (1 mil) zirconium diffusion barrier inside Al6061 aluminum cladding was selected for further development [6, 7]. Testing of this U-10Mo fuel form continues at the ATR, while the Fuel Fabrication Capability (FFC) pillar of $\mathrm{M}^{3}$ continues evaluation of fabrication of this fuel plate design [8].

A number of activities related to LEU fuel design for the ATR have been completed at INL. The primary focus has been on experimental materials performance studies for uranium-molybdenum composites. Experimental work has been supplemented by a number of computational fuel studies to determine potential performance of different fuel designs covering a broad range of fuel characteristics $[9,10,11,12]$. These analyses provided a basic understanding of the anticipated performance of an ATR loaded with LEU fuel. Conversion of the ATR and ATRC will involve major changes in the neutronic characteristics of both reactors. The effort has applied and will continue to require extensive computational reactor physics support for the following areas: engineering trade-off studies of various candidate LEU fuel elements, final engineering design of the preferred fuel element configuration, support of prototype testing in ATRC, initial LEU core startup of ATR itself, and follow-on operational support of ATR on a new, LEU-based fuel cycle. The engineering approach to conversion is being staged with pre-conceptual, conceptual, lead test assembly finalization and testing, and LEU conversion phases of development. A combination of design development, analysis and testing will be used to both qualify the ATR LEU fuel element and to implement LEU conversion.

A conceptual LEU fuel design has been developed assuming power peaking control through use of variable fuel meat thicknesses per fuel element plate and no use of burnable poison. Initially based on the fuel meat dimensions in the Integral Side-plate Burnable Absorber design proposed by Chang [11], an Enhanced LEU Fuel (ELF) design was proposed in which additional fuel mass was added to meet cycle performance issues. Two variations on 
this fuel are under investigation, identified as ELF Mk 1A and ELF Mk 1B. The ELF Mk 1A design uses three unique fuel meat thicknesses, which would reduce manufacturing costs. The ELF Mk 1B concept uses five unique fuel meat thicknesses to help flatten radial power peaking, but at the cost of two additional fuel thicknesses. Because the Mk 1B design has reduced power peaking relative to the Mk $1 \mathrm{~A}$ design, the latter has been assumed to be the bounding of the two designs in terms of safety analysis. Hence, ongoing safety analysis has focused on the ELF Mk 1A design. This paper describes the analysis performed to date in the design of the ELF element and the current status of safety analyses. This work has provided the best understanding of likely fuel performance absent in-core measurements; from this we draw conclusions about the general physics behavior of the Advanced Test Reactor fully loaded with LEU fuel. 


\section{FUEL ELEMENT MODEL}

In the ELF Mk 1A fuel element, the fuel meat within each fuel plate begins/ends $0.2413 \mathrm{~cm}$ from the element side plates. Figure 1 illustrates the edges of the 19 fuel plates and side plates for portions of two ELF Mk 1A fuel elements. Fuel meat regions are sandwiched within a $0.00254 \mathrm{~cm}(1 \mathrm{mil})$ thick zirconium barrier on each side of the fuel. Fuel meat thicknesses and other parameters are given in Table 1. Plate numbering begins at the innermost (minimum radius) plate and of course ends at plate 19, the outermost (maximum radius) plate. Note that the fuel meat is modeled as centered around the central radius of each plate, such that there is an equal thickness of aluminum on either side of the fuel/barrier region. Outer dimensions of fuel plates were unchanged from the HEU fuel design, such that flow channels all remain unchanged. This fuel represents a net increase in fuel meat mass from the pre-conceptual design in Ref. [13] in order to provide the capability to achieve the same cycle length as current HEU fuel. 


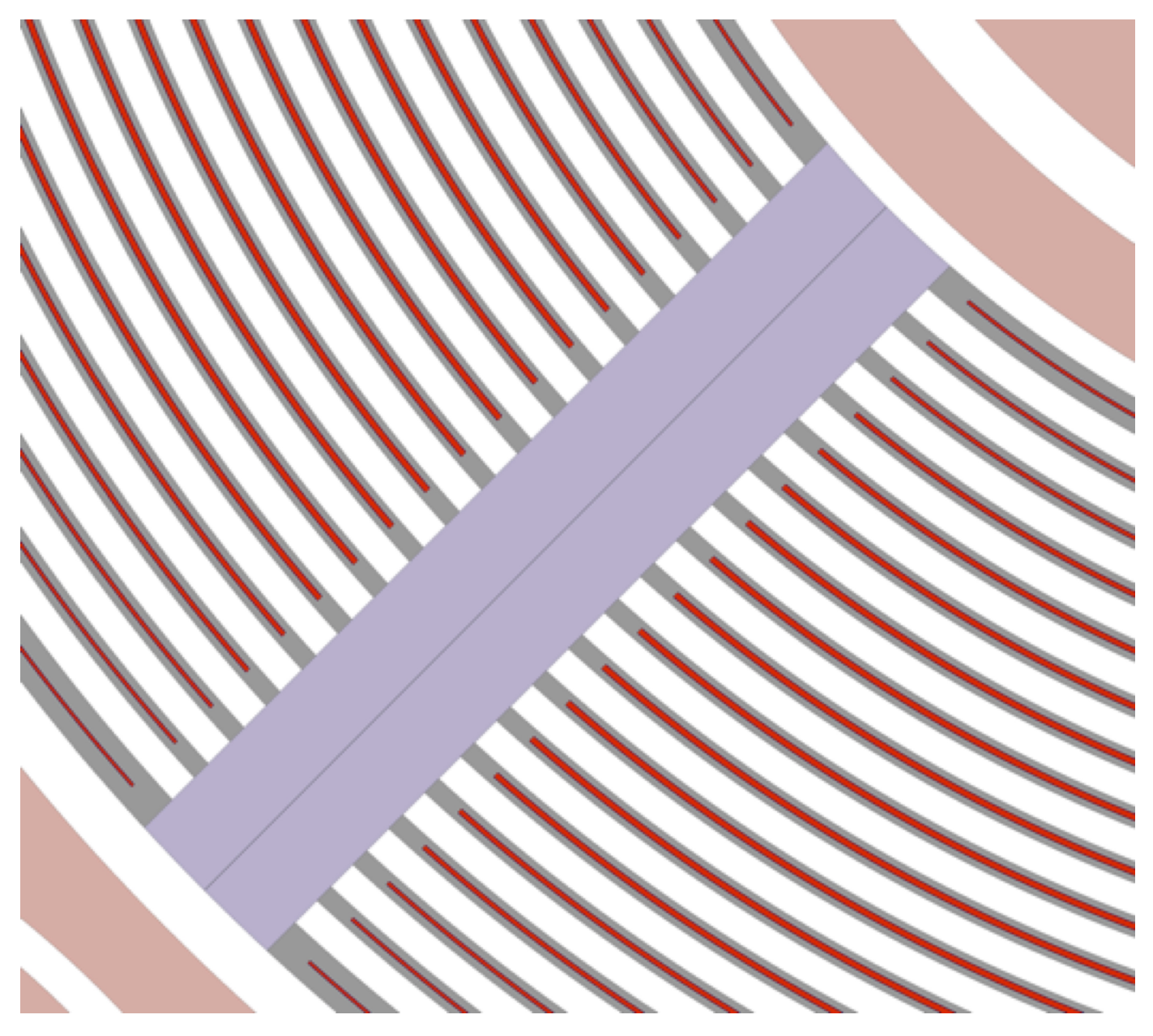

Figure 1: Serpent rendering of adjacent ELF fuel elements within ATR model. 
Table 1: Fuel Meat Dimensions for ELF Mk 1A Fuel Element Design.

\begin{tabular}{|c|c|c|c|c|c|}
\hline Plate \# & $\begin{array}{c}\text { Meat } \\
\text { Thickness } \\
(\text { mils })\end{array}$ & $\begin{array}{c}\text { Meat } \\
\text { Thickness } \\
(\mathrm{cm})\end{array}$ & $\begin{array}{c}\text { Inner Meat } \\
\text { Radius }(\mathrm{cm})\end{array}$ & $\begin{array}{c}\text { Meat Arc } \\
\text { Outer Meat } \\
\text { Radius }(\mathrm{cm})\end{array}$ & $\begin{array}{c}\text { Length } \\
(\mathrm{cm})\end{array}$ \\
\hline 1 & 8 & 0.0203 & 7.750 & 7.770 & 4.50 \\
2 & 13 & 0.0330 & 8.106 & 8.139 & 4.78 \\
3 & 13 & 0.0330 & 8.431 & 8.465 & 5.04 \\
4 & 16 & 0.0406 & 8.753 & 8.794 & 5.30 \\
5 & 16 & 0.0406 & 9.078 & 9.119 & 5.55 \\
6 & 16 & 0.0406 & 9.403 & 9.444 & 5.81 \\
7 & 16 & 0.0406 & 9.728 & 9.769 & 6.06 \\
8 & 16 & 0.0406 & 10.053 & 10.094 & 6.32 \\
9 & 16 & 0.0406 & 10.378 & 10.419 & 6.57 \\
10 & 16 & 0.0406 & 10.704 & 10.744 & 6.83 \\
11 & 16 & 0.0406 & 11.029 & 11.069 & 7.08 \\
12 & 16 & 0.0406 & 11.354 & 11.394 & 7.34 \\
13 & 16 & 0.0406 & 11.679 & 11.720 & 7.59 \\
14 & 16 & 0.0406 & 12.004 & 12.045 & 7.85 \\
15 & 16 & 0.0406 & 12.329 & 12.370 & 8.10 \\
16 & 13 & 0.0330 & 12.658 & 12.691 & 8.36 \\
17 & 8 & 0.0203 & 12.990 & 13.010 & 8.61 \\
18 & 8 & 0.0203 & 13.315 & 13.335 & 8.87 \\
19 & 8 & 0.0203 & 13.703 & 13.724 & 9.18 \\
\hline
\end{tabular}




\section{ANALYSIS METHODOLOGY}

With the exception of one calculations related to gamma fluxes, described later, the calculations reported herein were performed using Serpent Version 2.1.15 (July 31, 2013) [14] This is a pre-release beta version of this software package; however, all source code and the executable are controlled at INL. The software has not yet been formally qualified for safety analysis, and calculations reported here may not be used in Level 1 quality-controlled analysis. Verification and validation of Serpent are in progress under the LEU Conversion Project for use in such work, and validation analyses completed to date provide confidence in Serpent calculations.

All neutronic calculations were performed using ENDF/B-VII.0 cross sections as distributed with the Serpent 1.1.7 package [15], augmented by the thermal neutron $\mathrm{S}(\alpha, \beta)$ scattering treatment for beryllium from the MCNP5 tmccs data file [16]. The base model used for these calculations was derived from the 1994 ATR core internals changeout (94-CIC) clean core benchmark [17]. Analysis and definition of the original pre-conceptual ELF fuel design is provided in Ref. [13]. The current work describes revised calculations for the ELF Mk 1A fuel element design. Specifically, this work evaluates: (1) fuel element performance (e.g., reactivity and isotopic inventory as a function of burnup), (2) power distribution profiles and (3) reactor kinetics parameters for limiting power distributions. These data (heat source terms and kinetics parameters) were prepared to support thermal-hydraulic calculations performed using RELAP5/MOD2.5 [18] thermal-hydraulic calculations, and detailed ATR-SINDA [19] and SINDA-SAMPLE [20] fuel plate calculations, both for limiting hot-channel locations, for a variety of postulated accident scenarios. This paper will not detail the RELAP5 nor SINDA calculations or requirements; instead, we focus on the physics behavior of the LEU core as informed by the Serpent 2 analysis of an LEU-fueled ATR.

The physical configuration of the ATR, shown in Fig. 2, allows the reactor to be operated at different power levels in the corner lobes to allow for different testing conditions for multiple simultaneous experiments. The four lobes are identied by their compass locations: NW, NE, SW and SE. In Fig. 2; the top of the figure represents compass north. Power distributions in the ATR are controlled using outer shim control cylinders (OSCCs), rotating drums at the core periphery with a surface partially covered with hafnium. Neck shims are used for net reactivity control but not for power distribution shaping. These power distributions are referred to as power splits; for 
safety analyses, specific OSCC rotations are used to obtain the power splits used in different types of accident analysis. Specifically, two asymmetrical power splits: the $60 / 40$ and the $70 \mathrm{MW}$ splits, along with the balanced shim $50 / 50$ split, are used in safety limits calculations. The 60/40 split name is derived from a projected power distribution with $60 \mathrm{MW}$ in the SW lobe and $40 \mathrm{MW}$ in the NW and NE lobes, if the core were operated at a full 250 MW power level. However, in this split configuration, core power is actually operationally limited to 204.5 MW [21], as the SE lobe is administratively limited to a maximum of $60 \mathrm{MW}$. The $70 \mathrm{MW}$ power split is considered to be the enveloping case for safety analysis, and is based on $70 \mathrm{MW}$ power in the SE lobe with core power at $230 \mathrm{MW}$. The 50/50 split represents a core operating at $250 \mathrm{MW}$ with a nominal $50 \mathrm{MW}$ in each lobe. Twenty-four hafnium rods, neck shims, are located in the inner core neck regions, and are used for reactivity control. For this work, neck shims were not used; the model was set with all six neck shims located at the base of the NE and NW lobes fully inserted; in both the SE and SW lobes neck shim no. 4 was fully withdrawn, the remaining shims were fully inserted. These neck shims positions were set in the 94-CIC and not modified for these analyses.

The ATR contains nine primary flux traps. The highest flux positions (when OSCC drums are balanced and power has a nominal 50/50 split) are within the four core lobes, i.e., the NW, NE, SW and SW lobes. These are followed by flux traps in N, S, E and W positions, along with the central (C) flux trap. These flux traps don't play a direct role in the calculations reported in this work, although azimuthal power peaking is affected as a result of the core configuration near the flux trap locations, as described later in Section VI.A.

Much of the work described in this paper documents the first phase of safety analysis support work, performed for the ATR core fully loaded with fresh fuel. Safety analyses for end of cycle core loading is in progress, but indicates that safety limits are bounded by the fresh fuel core. Outside of safety calculations, additional analysis to support customer perfomance requirements used a simplified, representative core to capture the effects of burnup and to obtain end-of-life source terms. The following sections provide a description of the ELF Mk 1A design, demonstration of ability to meet minimum ATR performance requirements, initial calculations verification of the power split behavior for LEU; reactor kinetics parameters, reactivity coefficients and source term calculations. Finally, the paper concludes with comments on these results and plans for future work. 


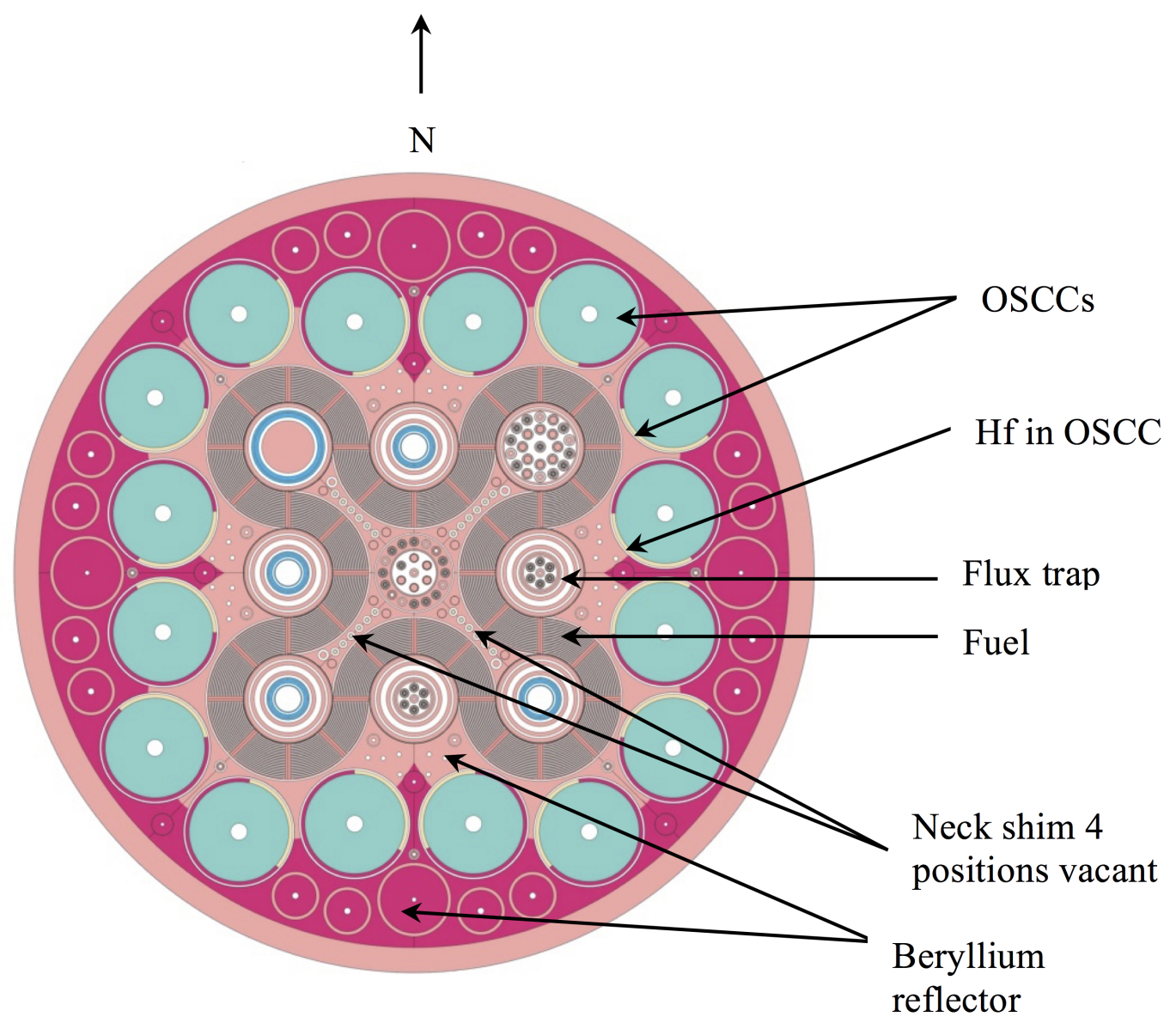

Figure 2: Cross-sectional view of the ATR core [17] 


\section{PERFORMANCE REQUIREMENTS}

With the selection of appropriate fuel plate thicknesses, it was demonstrated that the two ELF designs would yield similar radial power profiles to those of the current HEU fuel. However, five functional requirements were provided for LEU element designs [22, 23], and were used as the next criteria for evaluating the performance of fuel design before moving into safety analysis:

1. An operational cycle length of 56 days at $120 \mathrm{MW}$;

2. A fast-to-thermal neutron flux ratio within $\pm 5 \%$ of current values in pressurized-water loop test locations;

3. Greater than $4.8 \times 10^{14}$ fissions per second per gram ${ }^{235} \mathrm{U}$ in a specimen with one gram ${ }^{235} \mathrm{U}$ per linear inch in a standard in-pile tube (south corner lobes) operating at $60 \mathrm{MW}$;

4. A 3/1 lobe power split with south corner lobes operating at three times the lobe power of the northern lobes; and

5. Gamma-to-neutron flux ratio within $\pm 10 \%$ current values.

The four corner lobes of ATR (NW, NE, SW and SE) are referenced in power split configurations; pressurized water loops are located in the N, W, SE and SW positions. These are located in Fig. 2 by compass direction, with North located at the top of the figure as indicated.

To evaluate the ability of the core to satisfy these requirements, analysis of the various performance requirements as a function of burnup were performed assuming a representative core loading. This configuration would provide a more realistic approximation to isotopes present in the core during operation, using fuels with a variety of burnups. For the purposes of this simulation, it was assumed that the core was loaded with an assortment of fresh, once-burned, and twice-burned fuel elements. Based on discussion of loading philosophies with ATR operations staff and fuel loading examples from ATR cycles 145A and 151A [24], a representative core loading was assumed using 18 fresh assemblies, 14 once-burned assemblies, and 8 twice-burned assemblies, as illustrated in Fig. 3.

Using this core loading, the ELF fuel design was assessed and subsequently optimized based on the aforementioned performance criteria, as described below. 


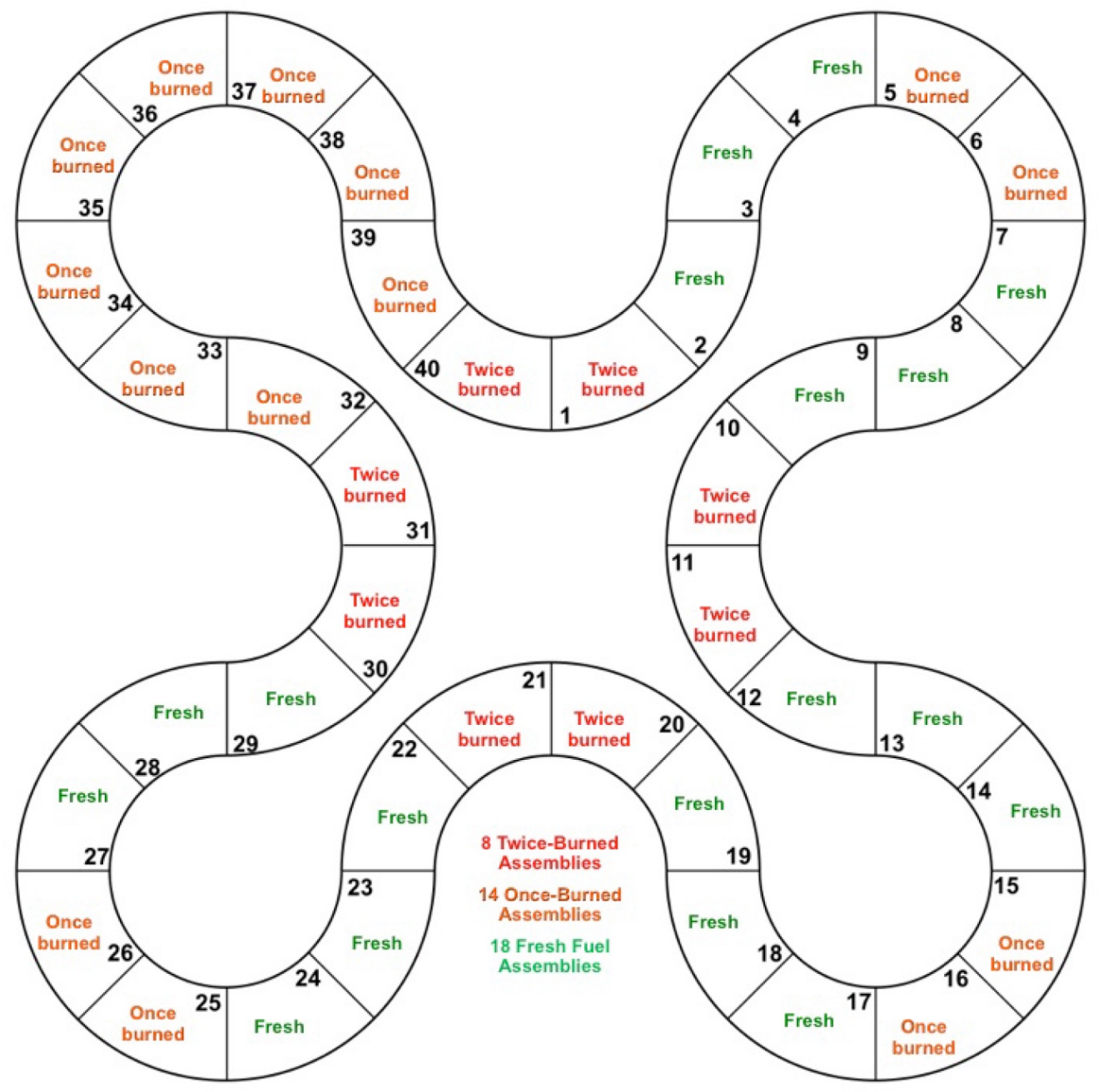

Figure 3: Loading pattern assumed for representative cycle calculations.

\section{IV.A. Cycle Length}

Calculations were performed to demonstrate that a core loaded with fresh fuel, with all OSCCs rotated to $80^{\circ}$ (mid-rotation in the OSCC $0^{\circ}$ to $160^{\circ}$ range) and fixed for the depletion cycle. The fixed rotation is an approximation to normal operation but represents and average rotation position and was felt to be appropriate for scoping calculations. The same approximation was applied to both HEU and LEU fuel to allow for direct comparison. The ELF design was shown to remain supercritical for an entire 56 day cycle at 
120 MW core power, although lacking burnable absorbers it showed a more significant decrease in reactivity over the cycle than HEU fuel. While this is not an issue for single cycle performance, the reduced reactivity would preclude three-cycle operation. Hence the pre-conceptual ELF design was adjusted by increasing the initial fuel loading to the thicknesses provided earlier in Table 1 to be able to match end of cycle HEU reactivity. The relative behavior of LEU fuel relative to HEU fuel is shown in Fig. 4. The second and third cycles show the effect of plutonium buildup in LEU due to successive captures in ${ }^{238} \mathrm{U}$.

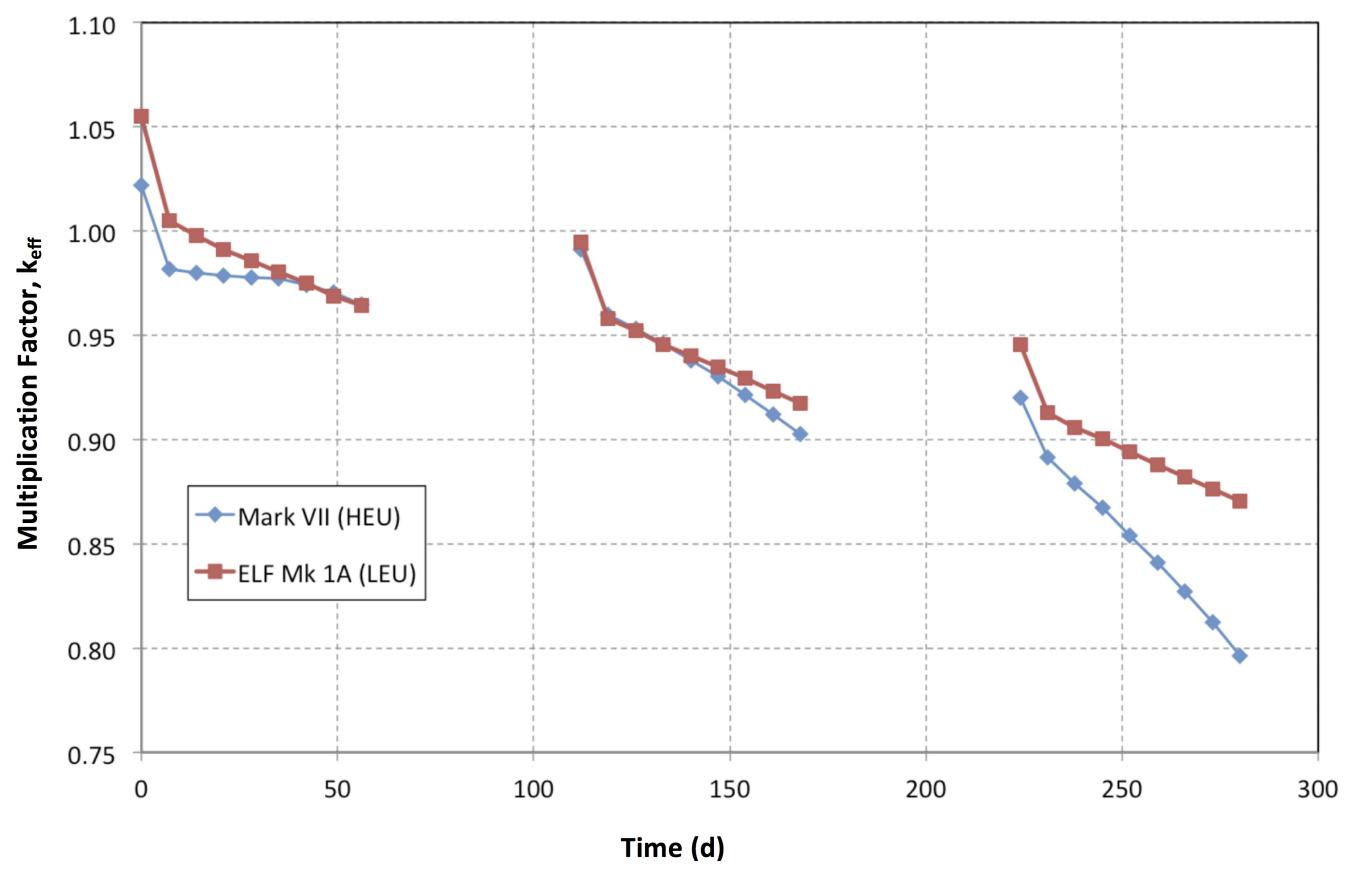

Figure 4: Comparison of $\mathrm{k}_{\mathrm{eff}}$ for HEU and ELF Mk 1A LEU fuel designs for three burn cycles

\section{IV.B. Fast/Thermal Flux Ratio}

The fast-to-thermal neutron flux ratio in the four pressurized loops was found to be about $3.5 \%$ higher, on average, than that of the HEU fuel at beginning of cycle, but exceeded $+5 \%$ near the end of cycle at an average of $5.2 \%$, as shown in Table 2. However, the reason for this difference is that the 
LEU ratio decreases more slowly with time than that of the HEU. For HEU, the fast-to-thermal ratio decreases by approximately $2.2 \%$ over a $56 \mathrm{~d}$ cycle; the LEU design showed a decrease of on the order of $0.5 \%$ over the same cycle length. Because from an experimental point of view it would be more desirable to maintain a more constant flux ratio over a cycle, and because the average difference over the length of the cycle remained less than $5 \%$, it was felt that the performance of the ELF design meets (and exceeds) the spirit of this requirement for the fast-to-thermal ratio. Note that the statistical uncertainty for fluxes in all calculations was less than $0.03 \%$.

Table 2: Percent Change in Fast to Thermal Flux Ratio for LEU Designs Relative to HEU Fuel for Pressurized Water Loop Locations

\begin{tabular}{lllllll}
\hline \multirow{2}{*}{ Lobe } & \multicolumn{7}{c}{ Burn Time $(\mathrm{d})$} \\
\cline { 2 - 7 } & 0 & 1 & 14 & 28 & 42 & 56 \\
\hline $\mathrm{N}$ & 3.9 & 4.0 & 4.5 & 4.9 & 5.3 & 5.9 \\
\hline $\mathrm{W}$ & 3.7 & 3.7 & 4.3 & 4.7 & 5.5 & 5.8 \\
\hline $\mathrm{SW}$ & 4.1 & 3.9 & 4.3 & 5.0 & 5.3 & 5.6 \\
\hline $\mathrm{SE}$ & 3.8 & 4.1 & 4.6 & 4.9 & 5.0 & 5.5 \\
\hline
\end{tabular}

\section{IV.C. Specimen Fission Rate}

Assuming a nominal water density corresponding to a core moderator temperature of $388 \mathrm{~K}$, the ELF-fueled core was found to meet the $4.8 \times 10^{14}$ fissions per second per gram ${ }^{235} \mathrm{U}$ criterion, although showing a slightly lower fission rate than seen in HEU fuel. However, it was later learned that the requirement was intended to be specified for an experiment with a moderator density of $0.75 \mathrm{~g} / \mathrm{cm}^{3}$ (reactor conditions). At that water density, neither LEU not HEU would meet the $4.8 \times 10^{14}$ fissions per second per gram ${ }^{235} \mathrm{U}$ criterion. However, in both cases the fission rate was found to be approximately $5 \%$ lower in the SW lobe and $2.2 \%$ in the SE lobe with the ELF core at the same power. Either redesign of the experiment (increased moderation) or an increase lobe power will be necessary to offset this effect. An increase in lobe power may be evaluated as a part of the core redesign process; modern analysis methods will allow reduction of some of the conservatisms used in setting existing power limits. 


\section{IV.D. Power Split}

For the purposes of this study, it was assumed that the power split is defined as the ratio of the sum of the powers in 16 fuel elements associated with the SE and SW lobes to that of the sum of the powers in the corresponding 16 elements in the NE and NW lobes. To this end, the mixed-loading core was used, the eight northern OSCCs were set to $0^{\circ}$ rotation (poisoned region fully facing associated elements), and calculations were performed with the southern eight $\mathrm{OSCC}$ set at angles of $95^{\circ}, 100^{\circ}, 105^{\circ}, 110^{\circ}, 115^{\circ}$ and $120^{\circ}$ respectively to obtain the core power distributions as a function of southern drum rotation. Results are provided in Table 3 and show that for a given rotation angle for southern OSCCs, ELF fuel provides a slightly larger power tilt than for HEU fuel, with a larger eigenvalue. For these calculations, the statistical uncertainty for all calculations was less than $0.01 \%$.

Table 3: Core S/N Lobe Power Ratios for HEU and LEU Fuels

\begin{tabular}{ccc|cc}
\hline \multicolumn{3}{c|}{ HEU } & \multicolumn{2}{c}{ LEU } \\
\hline $\begin{array}{c}\text { OSCC rotation } \\
\text { angle (degrees) }\end{array}$ & $\begin{array}{c}\text { S/N Flux Trap } \\
\text { Power Ratio }\end{array}$ & $\mathrm{k}_{\text {eff }}$ & \multicolumn{2}{c}{$\begin{array}{c}\text { S/N Flux Trap } \\
\text { Power Ratio }\end{array}$} \\
\hline 95 & 2.78 & 1.003 & 3.06 & 1.011 \\
100 & 2.88 & 1.007 & 3.19 & 1.014 \\
105 & 2.99 & 1.011 & 3.32 & 1.018 \\
110 & 3.07 & 1.014 & 3.43 & 1.022 \\
115 & 3.16 & 1.016 & 3.55 & 1.026 \\
120 & 3.26 & 1.019 & 3.62 & 1.028 \\
\hline
\end{tabular}

\section{IV.E. Gamma/Neutron Ratio}

At the time of the initial calculations, Serpent 2 was unable to perform coupled neutron/gamma calculations. Thus, the MC21 code [25] was used. MC21 has been developed and used by DOE Naval Reactor facilities for reactor calculations including the ATR. MC21 initially calculated that the gamma/neutron ratio in the LEU-fueled core was about $40 \%$ less than that of the HEU-fueled core. This was not unexpected; the higher mass of LEU fuel, due to approximately ten times the mass of ${ }^{238} \mathrm{U}$, is an effective gamma shield. It is highly likely that this attenuation would be seen in any LEU fuel, and the details of the fuel design are irrelevant. However, it was later determined that the gamma source is necessary for experiment heating. Hence, low energy 
gammas are small contributors and it was assumed that the only gamma flux of interest is that above $1 \mathrm{MeV}$. Fluxes above this energy have seen very little attenuation and thus are insensitive to the fuel mass, and are more sensitive to the initial gamma spectrum. With this assumption, the gamma-to-neutron ratio in the LEU core were found to be approximately $10 \%$ lower than for the HEU core. Again, much or all of this reduction would be recovered if the lobe was operated at a higher power. 


\section{POWER SPLITS}

These analyses focus on the three lobe power splits described earlier to demonstrate power distributions for the normal, representative, and limiting lobe power, or 50/50, 60/40 and $70 \mathrm{MW}$ splits, respectively. Historically, these splits also provide the basis for power distributions and peaking factors to determine limiting cases for steady state operation and transient analysis. These cases cover the maximum range of the expected operating conditions and were selected to show both nominal and maximum values of core parameters and the sensitivity of these parameters to variations in the core loading and operation. Calculations previously performed for HEU fuel using PDQ [26] utilizing these configurations are described in Ref. [21], which also provides the OSCC rotations used to obtain these power splits; these OSCC rotations and shim positions are also given in Table 4. To see if these splits could be reproduced, an updated Serpent ATR/ELF model (ATR 94-CIC configuration with HEU fuel replaced by the modified ELF design) was used with OSCCs rotated to the quadrant control drum rotations provided in the table.

Table 4: Summary of Shim Positions for Three Power Splits [21]

\begin{tabular}{|c|c|c|c|c|c|c|c|c|}
\hline \multirow{4}{*}{$\begin{array}{l}\text { Power } \\
\text { Split }\end{array}$} & \multicolumn{2}{|c|}{ NW Lobe } & \multicolumn{2}{|c|}{ NE Lobe } & \multicolumn{2}{|c|}{ SW Lobe } & \multicolumn{2}{|c|}{ SE Lobe } \\
\hline & Outer & Neck & Outer & Neck & Outer & Neck & Outer & Neck \\
\hline & Shims & Shims & Shims & Shims & Shims & Shims & Shims & Shims \\
\hline & (deg.) & Inserted & (deg.) & Inserted & (deg.) & Inserted & (deg.) & Inserted \\
\hline $50 / 50$ & 56.6 & 123456 & 56.6 & 123456 & 56.6 & $123-56$ & 56.6 & $123-56$ \\
\hline $60 / 40$ & 40.1 & 123456 & 46.5 & 123456 & 69.7 & $123-56$ & 56.5 & $123-56$ \\
\hline $70 \mathrm{MW}$ & 0.0 & 123456 & 0.0 & 123456 & 89.8 & $123-56$ & 104.2 & $123-56$ \\
\hline
\end{tabular}

Serpent power predictions compare favorably with the earlier 3D PDQ calculations for the 60/40 and 70 MW splits, as illustrated in Figs. 5 and 6, respectively. Note that the Serpent calculations are not a direct comparison to the PDQ results, as these new calculations have been performed using a core fully loaded with the ELF Mk 1A design. However, this plot does show that even with the significantly changed fuel element design, peak power elements are consistent between the two models. For the 60/40 power split, the hot (maximum power) element was found to be Element 23 (SW lobe); for the 70MW split, the limiting element was calculated to be Element 18 (SE lobe). Figure 6 shows the results of calculations for the 50/50 split; results show a uniform power tilt with higher powers in the southern lobes. An independent calculation with MCNP5 [16] shows the same trend. It is 
beleived that this behavior is due to spectral changes in the ELF design relative to HEU fuel. For the 60/40 and $70 \mathrm{MW}$ splits powers are shifted toward the south; hence north vs south differences are obscured.

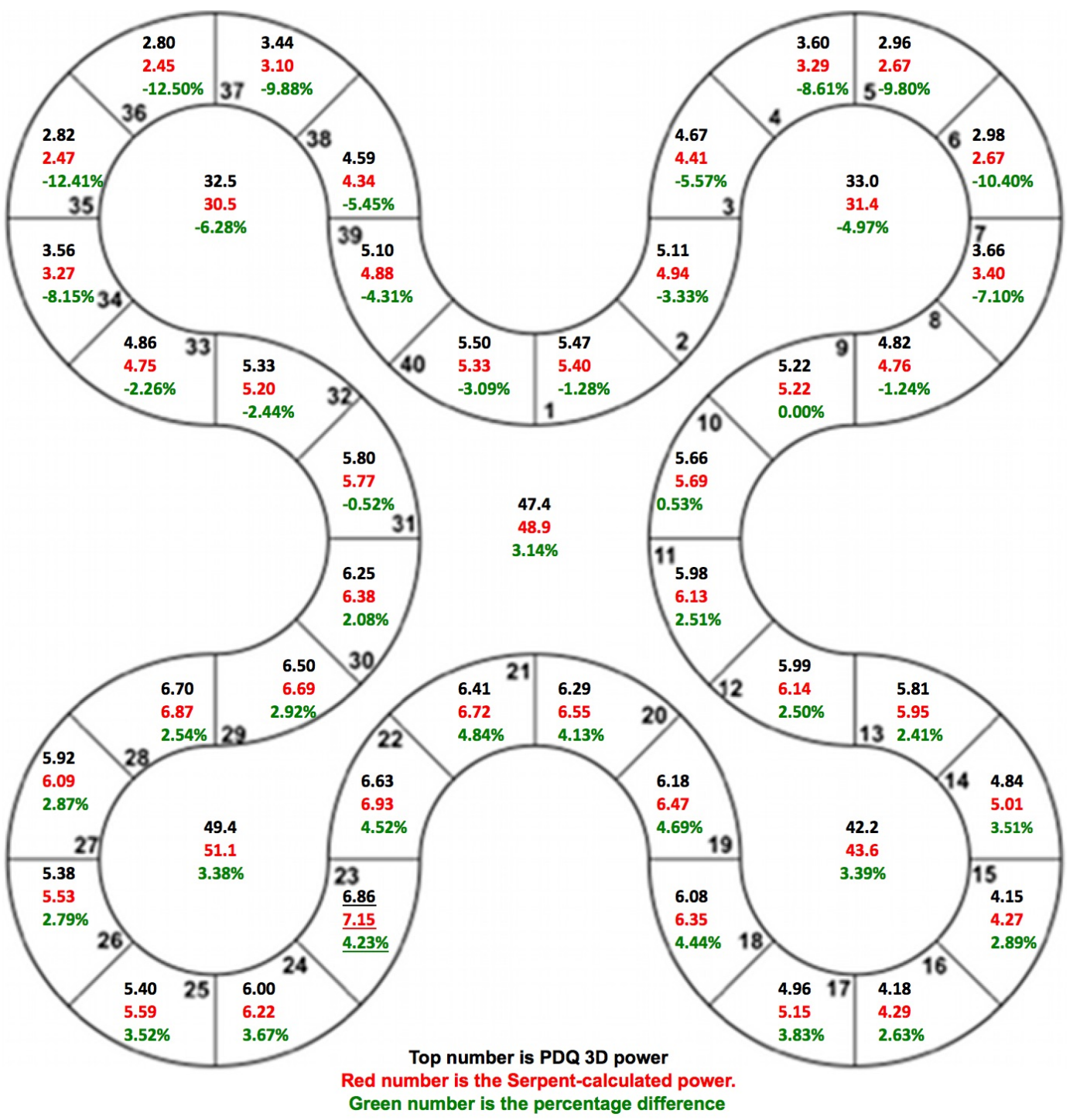

Figure 5: Comparison of PDQ (3D) predicted powers with HEU fuel [21] and Serpent fuel element powers with LEU ELF Mk 1A fuel for 60/40 split (204.5 MW core power) 


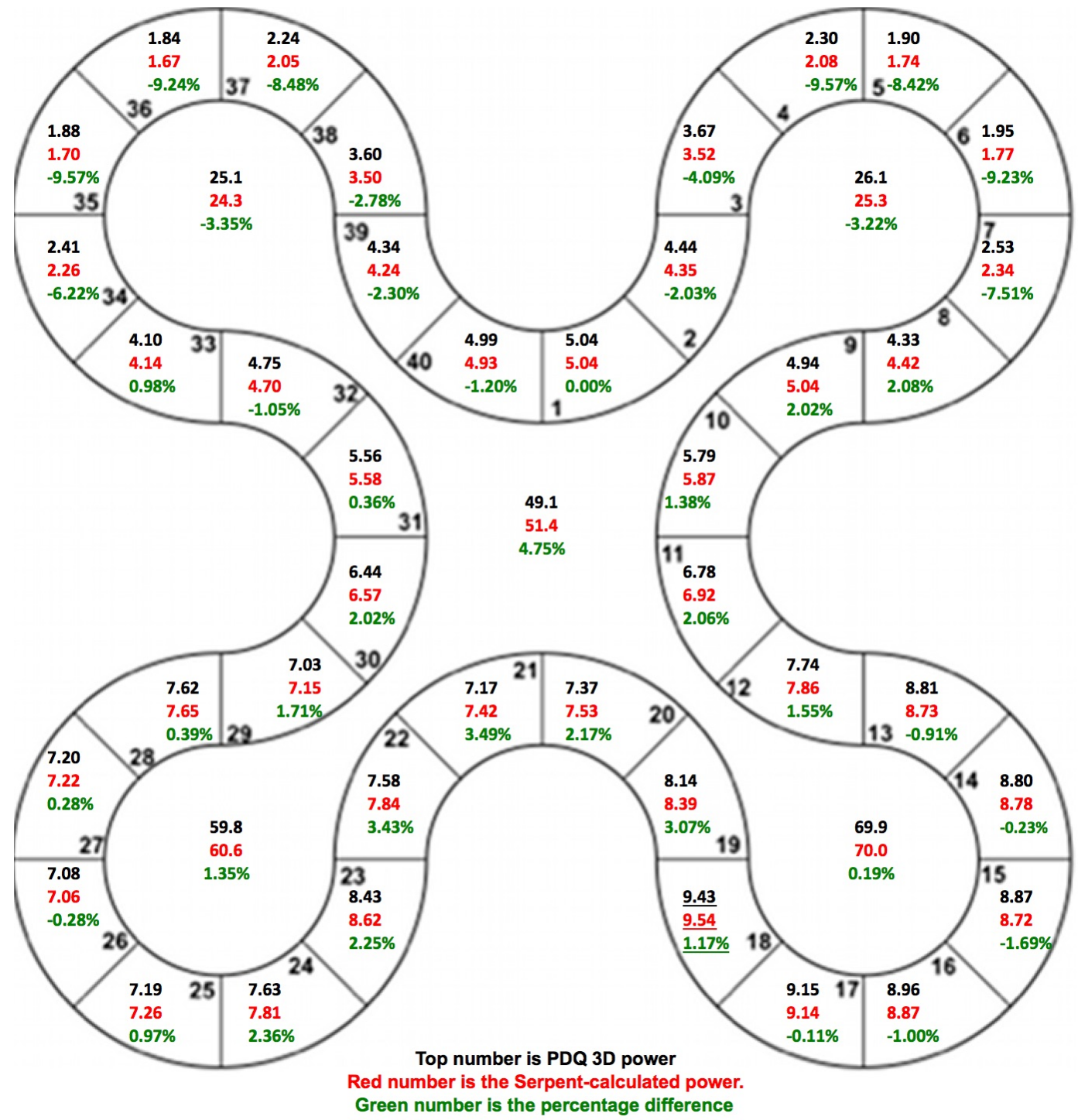

Figure 6: Comparison of PDQ (3D) predicted powers with HEU fuel [21] and Serpent fuel element powers with LEU ELF Mk 1A fuel for $70 \mathrm{MW}$ split (230 MW core power) 


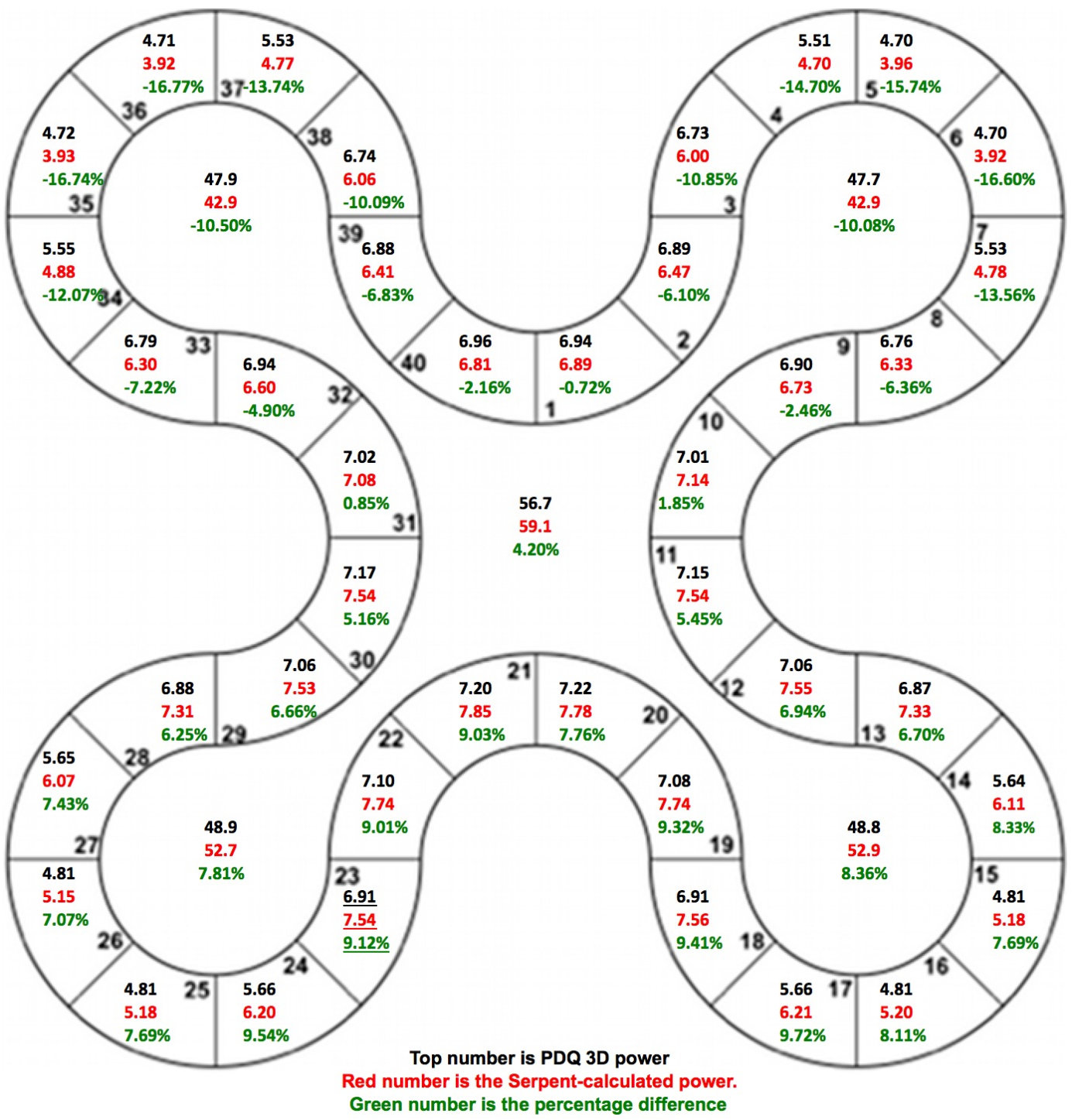

Figure 7: Comparison of PDQ (3D) predicted powers with HEU fuel [21] and Serpent fuel element powers with LEU ELF Mk 1A fuel for 50/50 split (250 MW core power) 


\section{SPATIAL POWER DISTRIBUTIONS}

To calculate spatial power distributions in the hot element for the 70 MW and 60/40 power splits, the ATR-SINDA analysis requested separate azimuthal axial power density distributions within each of the 19 fuel plates, to follow the procedures used in historical HEU analysis. The peak power is identified as the product of the nominal core power $P_{\text {core }}$ and the maximum power peaking factor. In SINDA, the maximum peaking factor is calculated in terms of the point-to-core-average power density function and the pointto-plate-average

The azimuthal and axial peaking factors were calculated independently by slightly different approaches, as described in the following sub-sections.

\section{VI.A. Azimuthal Power Distributions}

Azimuthal power distribution calculations were needed only for the 70 MW and 60/40 power splits. Thus, these two Serpent models were updated to provide fission power tallies in each of the respective limiting fuel elements both azimuthally and axially. For the azimuthal distribution, each of the fuel meat regions (shown in dark red in each fuel plate in Fig. 1) was divided into 20 uniform regions, each representing a $2.25^{\circ}$ arc within the fueled regions. Powers were calculated for each of the 20 azimuthal regions and for each for the 19 fuel plates. The fuel meat was equally distributed in all arcs; each arc segment contained 1/20 of the fuel meat within each fuel plate. Volumes for fuel in each plate and within each segment of each plate are given in Table 5 .

Table 5: Fuel Meat Volumes in ELF Mk 1A Fuel Element

\begin{tabular}{ccc|ccc}
\hline $\begin{array}{c}\text { Plate } \\
\text { No. }\end{array}$ & $\begin{array}{c}\text { Fuel Volume } \\
\left(\mathrm{cm}^{3}\right)\end{array}$ & $\begin{array}{c}\text { Fuel Volume Per } \\
\text { Arc Segment }\left(\mathrm{cm}^{3}\right)\end{array}$ & $\begin{array}{c}\text { Plate } \\
\text { No. }\end{array}$ & $\begin{array}{c}\text { Fuel Volume } \\
\left(\mathrm{cm}^{3}\right)\end{array}$ & $\begin{array}{c}\text { Fuel Volume Per } \\
\text { Arc Segment }\left(\mathrm{cm}^{3}\right)\end{array}$ \\
\hline 1 & 11.15 & 0.5573 & 11 & 35.09 & 1.7547 \\
2 & 19.26 & 0.9631 & 12 & 36.36 & 1.8179 \\
3 & 20.29 & 1.0145 & 13 & 37.62 & 1.8812 \\
4 & 26.24 & 1.3119 & 14 & 38.89 & 1.9445 \\
5 & 27.50 & 1.3751 & 15 & 40.15 & 2.0077 \\
6 & 28.77 & 1.4384 & 16 & 33.65 & 1.6827 \\
7 & 30.03 & 1.5016 & 17 & 21.34 & 1.0671 \\
8 & 31.30 & 1.5649 & 18 & 21.98 & 1.0988 \\
9 & 32.56 & 1.6282 & 19 & 22.73 & 1.1366 \\
10 & 33.83 & 1.6914 & & & \\
\hline
\end{tabular}


Powers were requested in the form of a point-to-core-average power density ratio, where a "point" was a $1 / 20$ arc segment in a single fuel plate. For each of the two power splits, the point-to-core-average power ratio in the limiting element was calculated for each azimuthal segment by dividing the power in that segment by volume in that segment. This was then divided by the average power density in all fuel elements in the core, $q_{\text {fuel }}^{\prime \prime \prime}$, i.e.,

$$
\hat{p}_{i, j}=\frac{\left(\frac{P_{i, j}}{V_{i, j}}\right)}{\left(\frac{\sum_{j=1,19} \sum_{i=1,20} P_{i, j}}{\sum_{j=1,19} \sum_{i=1,20} V_{i, j}}\right)}=\frac{q_{i, j}^{\prime \prime \prime}}{q_{\text {fuel }}^{\prime \prime \prime}}
$$

Calculations were performed using 100 active cycles with 20,000,000 neutron simulations per cycle, i.e, $2 \times 10^{9}$ neutron histories, after 5 inactive cycles used to calculate an initial neutron source distribution. This rather large number of histories was used to minimize statistical fluctuation in fission power tallies in each azimuthal region. Figures 8 and 9 illustrate the azimuthal point-to-core average power density for the 60/40 (limiting element 23 in SW lobe) and 70 MW (limiting element 18 in the SE node) power splits, respectively. Although trends are clear in the data, statistical fluctuations are still seen. Error bars were omitted for clarity.

Inspecting the two figures, a number of general observations can be made. First, the highest power density peaking occurs in the innermost and outermost fuel plates. This is due to increased moderation by water regions immediately inside plate 1 and outside plate 19, and due to spatial self shielding. It is important to note, however, that these plates have, by design, reduced fuel thickness, to decrease the total power and corresponding heat flux within the flow channel. Next, for these two limiting element locations, the power on the outer plates is higher than in the inner plates, primarily because the inner plates are in close proximity to the SW and SE flux traps, both of which are identical (in this model) and contain concentric annular cylinders of aluminum, stainless steel, helium and water. The outer plates, on the other hand, see primarily the beryllium reflector with very little hafnium due to OSCC rotations. Finally, it is clear that, in general (and especially for plates 3-17), the left and right edges see more peaking than the interior segments. This is again due to increased moderation (water gaps between 


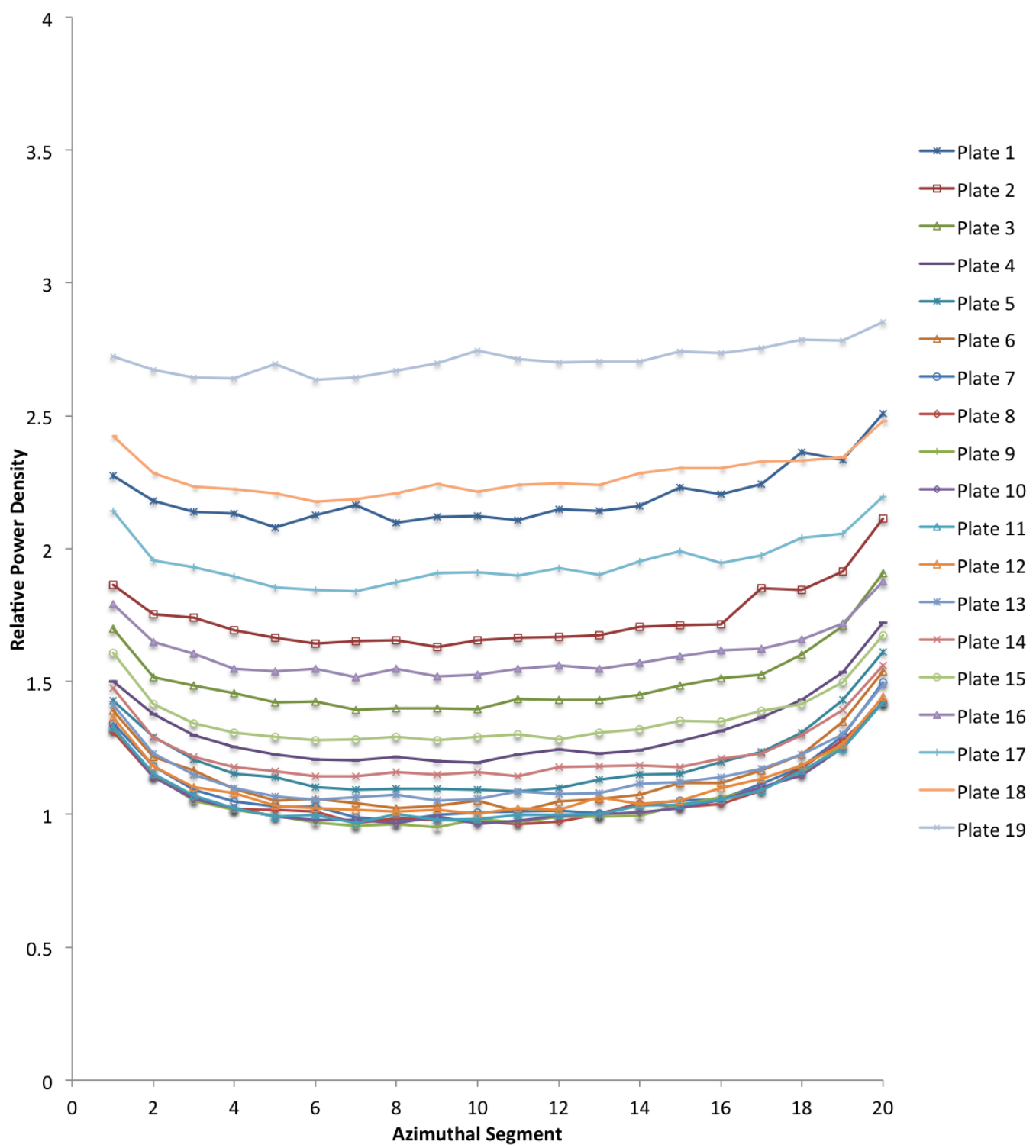

Figure 8: Azimuthal power densities for 60/40 power split at beginning of life)

elements and to some extent aluminum side plates) along with more spatial self shielding effects.

For the 60/40 split, the SW lobe has the highest total power, as shown in Fig. 5, at 51.1 MW. The lobe power is determined as the sum of the 


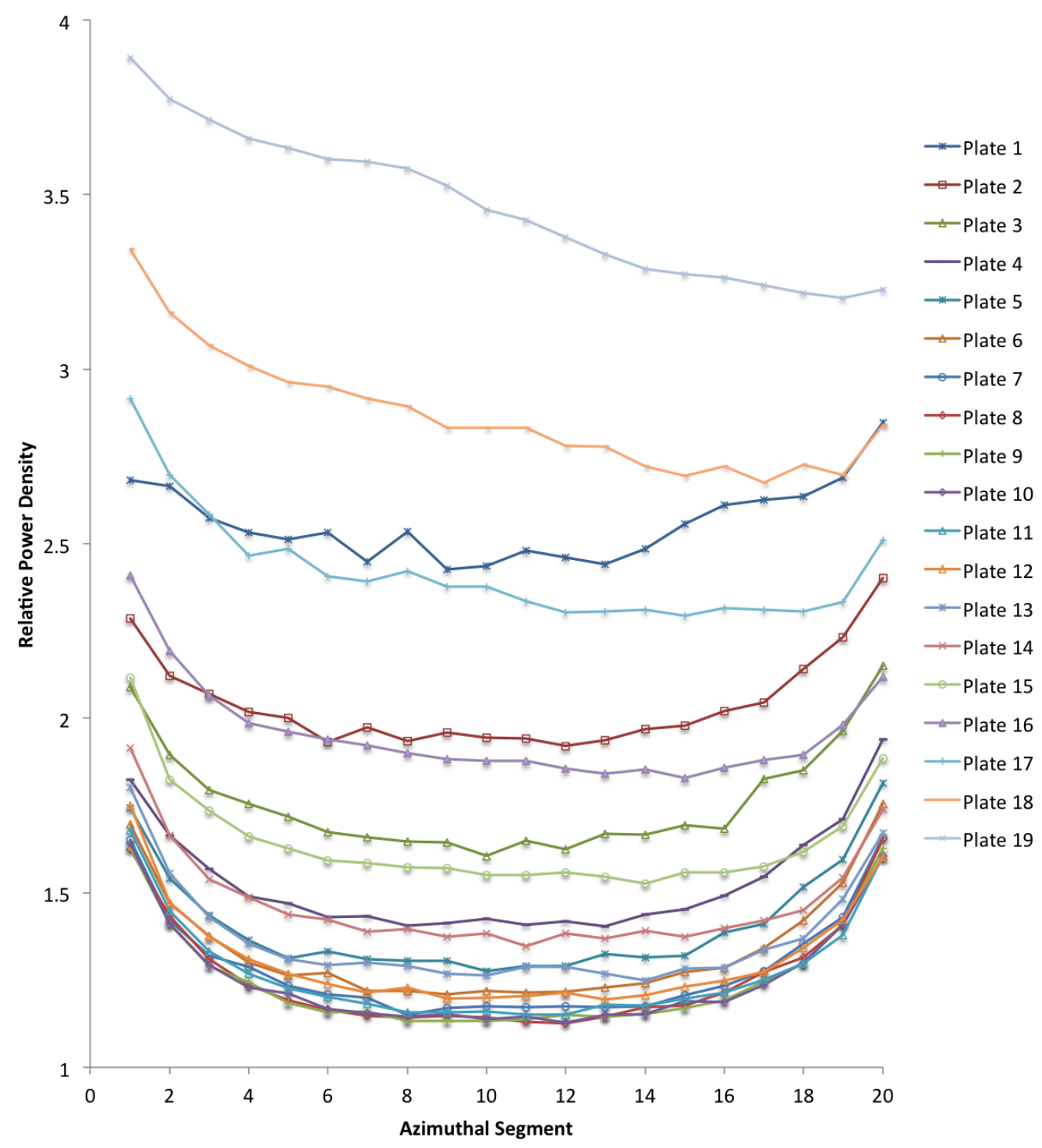

Figure 9: Azimuthal power densities for $70 \mathrm{MW}$ power split at beginning of life

eight fuel elements surrounding the lobe. In the SW lobe, this corresponds to elements 22-29. Element 23 has the highest power, due primarily to the rotation of the OSCCs for this power split; SW OSCCs are rotated to $89.8^{\circ}$; for reference, Fig. 2 shows all drums rotated to $51.8^{\circ}$, with increasing angle of rotation moving the hafnium segment on the beryllium OSCC drums away 
from the core. Figure 8 shows that the highest power density peaking occurs in segment 20 of fuel plate 19. The segments are numbered from 1 to 20 moving left to right when the inner fuel plate is oriented at the bottom and the outer plate at the top. Hence segment 20 in element 23 is adjacent to segment 1 in element 24, and plate 19 in element 23 is facing the $\mathrm{S}$ flux trap. For this power split, the SW OSCCs have the highest outward rotation (hafnium region rotated away from the fuel). The power peaking is relatively flat for plate 19, although the peak is at the right hand side of the element, furthest away from the $\mathrm{S}$ flux trap.

For the $70 \mathrm{MW}$ split, the SE lobe has the highest total power, as shown in Fig. 6, at $70 \mathrm{MW}$ (hence the $70 \mathrm{MW}$ split name). For this power split, the SE OSCCs have the greatest outward rotation. In the SE lobe, the lobe power is the sum of the powers in elements 12-19. Element 18 (which is symmetrically located in the SE lobe to element 23 in the SW lobe) has the highest total power, again due to the rotation of the OSCCs for this power split. In this case, the OSCC rotation is even more severe, rotated out to $104.2^{\circ}$. Figure 9 shows that the highest power peaking occurs in segment 1 , the left hand side of fuel plate 19, adjacent to element 17 . Unlike the 60/40 split, the power density peaking increases significantly moving right to left on plate 19, although the shape of the peaking approaches a linear change with angle.

\section{VI.B. Axial Power Distributions}

As with the azimuthal distribution, axial power distribution calculations were requested only for the peak power assemblies in the $70 \mathrm{MW}$ and 60/40 power splits (although axial discretization was performed for the 50/50 split for core heating calculations, as discussed later). For these two power splits the axial power distribution over the $121.92 \mathrm{~cm}$ (48 in.) height of the fuel element was divided into 10 uniform regions, each representing a $12.192 \mathrm{~cm}$ (4.8 in.) axial segment within the fuel. Powers were calculated for each of the 10 axial regions for each for the 19 fuel plates in the respective peak power assemblies.

Figures 10 and 11 illustrate the relative axial power density for the $70 \mathrm{MW}$ and 60/40 power splits, respectively. The normalized axial power $\hat{P}_{k, j}$ was calculated for each axial segment $\mathrm{k}$ in plate $\mathrm{j}$ as the segment power divided by the average power in the full height of the plate, i.e., 


$$
\bar{P}_{k, j}=\frac{P_{k, j}}{\frac{1}{10} \sum_{k=1,10} P_{k, j}}
$$

Axial zones are numbered axially from the top to bottom of the fuel element in the two figures.

\section{VI.C. Peak Power Calculation}

Axial and azimuthal profiles are combined to develop a conservative estimate of the peak power that could occur for a given power split. Peak power magnitude and location were determined from the assumed core power, the point-to-core-average power density and the plate-normalized power density use the following:

$$
P_{\text {max }}=P_{\text {core }} \cdot \max \left(\left(\left(\left(\frac{\hat{p}_{p l, a z} \cdot \frac{V_{p l}}{20} \cdot \frac{\bar{p}_{p l, a x}}{10}}{V_{\text {core }, \text { fuel }}}\right), p l=1,19\right), a z=1,20\right), a x=1,10\right)
$$

where: $\hat{p}_{p l, a z}=$ Point-to-Core-Average power density in azimuthal zone $a z$ of fuel in plate $p l$,

$\bar{p}_{p l, a x}=$ Plate-normalized power density in axial zone $a x$ of fuel in plate $p l$,

$V_{p l} \quad=$ Volume of fuel in plate $p l$,

$V_{\text {core, fuel }}=$ Total volume of all fuel in core.

Note that azimuthal power densities are weighted by the volume of each azimuthal zone, as the volume changes by plate. However, for axial power densities, because they are computed per plate all have the same volume, and each axial zone has the same weight. 


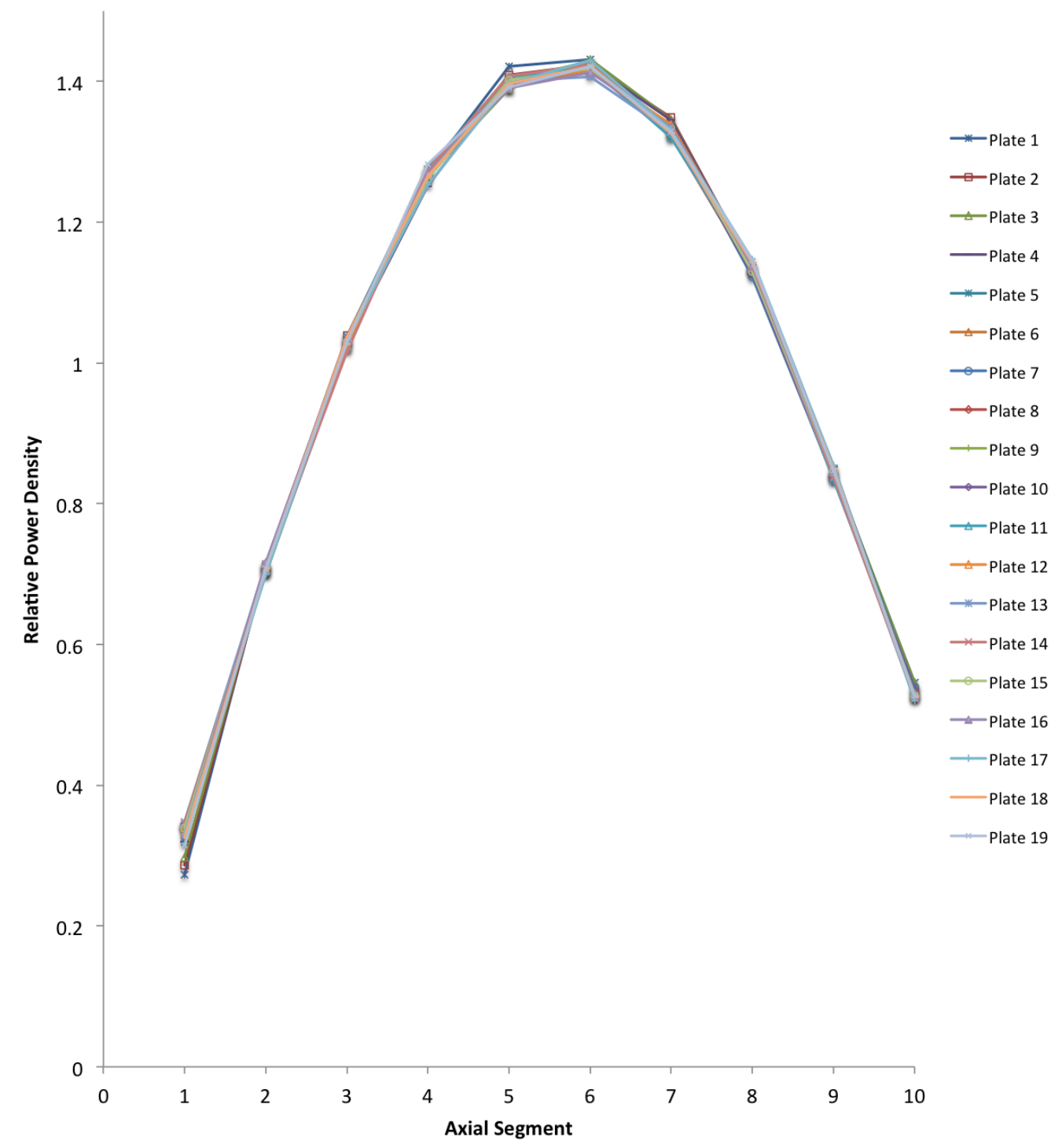

Figure 10: Normalized axial power densities for $70 \mathrm{MW}$ power split at beginning of life. 


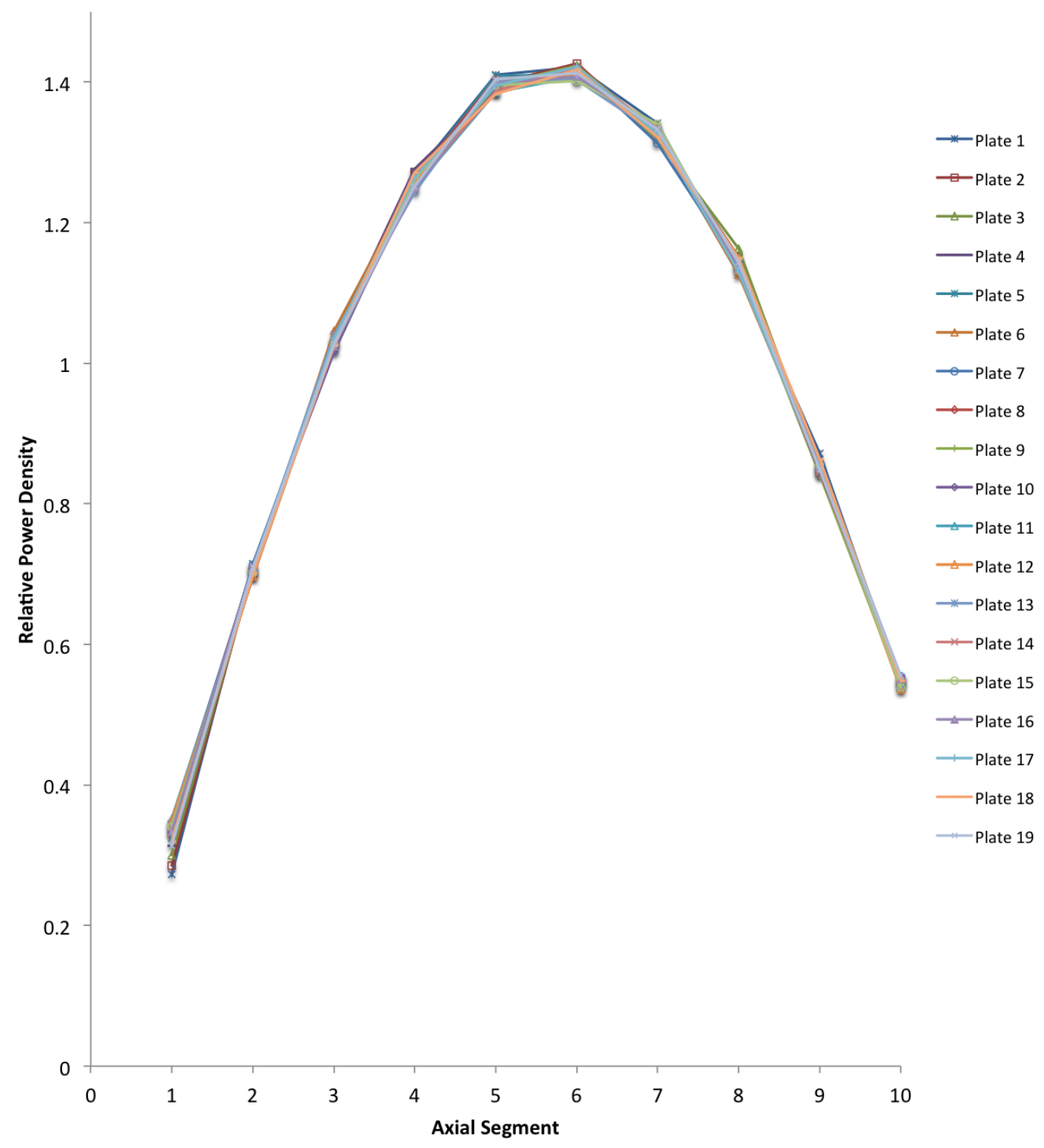

Figure 11: Normalized axial power densities for $60-40$ power split at beginning of life. 


\section{REACTOR KINETICS PARAMETERS}

Table 6 provides the reactor kinetics parameters calculated by Serpent for the three power splits. The value of $\beta_{\text {eff }}$ changes very little with the three configurations; in fact, the values are statistically identical, and an average value was provided as a recommended value for all calculations. The values for $\beta_{\text {eff }}$ are also consistent with that of the HEU core (Serpent calculates a value of 0.00708 for $\mathrm{HEU}$ fuel in the 94-CIC configuration). However, note that unlike HEU fuel, this value is expected to decrease with burnup for LEU fuel.

Table 6: LEU Fuel Kinetics Parameters

\begin{tabular}{lcccc}
\hline Parameter & $\begin{array}{c}70 \text { MW Power } \\
\text { Split }\end{array}$ & $\begin{array}{c}\text { 60-40 Power } \\
\text { Split }\end{array}$ & $\begin{array}{c}50-50 \text { Power } \\
\text { Split }\end{array}$ & $\begin{array}{c}\text { Recommended } \\
\text { Value }\end{array}$ \\
\hline $\begin{array}{l}\text { Effective DelayedNeutron } \\
\text { Neutron Fraction, } \beta_{\text {eff }}\end{array}$ & $7.0831 \mathrm{E}-03$ & $7.1065 \mathrm{E}-03$ & $7.122 \mathrm{E}-03$ & $7.10 \mathrm{E}-03$ \\
${ }^{239} \mathrm{U}$ Yield Factor & $1.4923 \mathrm{E}-01$ & $1.5237 \mathrm{E}-01$ & $1.523 \mathrm{E}-01$ & $1.51 \mathrm{E}-01$ \\
Prompt Neutron & $3.6526 \mathrm{E}-05$ & $3.1458 \mathrm{E}-05$ & $3.1397 \mathrm{E}-05$ & No Recommendation \\
Generation Time, $\ell(\mathrm{s})$ & & & & \\
\hline
\end{tabular}

RELAP5 input includes a ${ }^{239} \mathrm{U}$ yield factor, which is used in the calculation of actinide decay heat. This value is calculated as the ratio of capture in ${ }^{238} \mathrm{U}\left({ }^{239} \mathrm{U}\right.$ production) to total fission for the full core. However, this value is expected to increase significantly for LEU fuel, as indicated by the results in Table 6. LEU fuel with greater than $80 \%{ }^{238} \mathrm{U}$ will result is significantly greater yield of ${ }^{239} \mathrm{U}$. At present, the Serpent-calculated values for the ${ }^{239} \mathrm{U}$ yield factor should be assumed to be correct until a reason for the discrepancy between reported and calculated HEU yield factors can be determined.

The prompt generation time values calculated by Serpent differ between the $70 \mathrm{MW}$ power split case and the other two core configurations. Therefore, it is recommended that the value be changed accordingly based on the assumed configuration of the transient of interest. 


\section{REACTIVITY COEFFICIENTS}

In order to perform transient simulation of the ATR, a set of reactivity coefficients for both fuel temperature (Doppler) and moderator density. Fuel temperture and moderator density reactivity coefficients are provided in Tables 7 and 8, respectively. These coefficients are global parameters in which the parameter of interest (i.e., temperature, moderator density) was set to a number of different values on a core-wide level within the Serpent model.

For the Doppler coefficient, input fuel temperatures in all fuel materials were varied from $68 \mathrm{~F}$ to $700 \mathrm{~F}$ and $\mathrm{k}_{\text {eff }}$ was calculated for each state. Reactivity $(\Delta \mathrm{k} / \mathrm{k})$ was calculated relative to $\mathrm{k}_{\mathrm{eff}}$ for a nominal operating temperature of $239 \mathrm{~F}$, then changed to units of dollars by dividing by the recommended value of 0.0071 for $\beta_{\text {eff }}$ (from Table 6 ). In these calculations, changes in $\mathrm{k}_{\text {eff }}$ were relatively small and subject to statistical variation, but showed a very linear trend. To eliminate the statistical effect, a linear fit was applied to each set of data and used to generate the reactivities provided in Table 7 .

Moderator (water coolant) reactivity was also calculated in terms of $\Delta \mathrm{k} / \mathrm{k}$ (in dollars) as a function of water density, relative to a nominal moderator density of $62.05 \mathrm{lb} / \mathrm{ft}^{3}$. Water is present in a number of locations in the ATR model, both as a unique mixture and homogenized with other mixtures. However, for these calculations moderator density was perturbed only for the water located within the flow channels adjacent to the fuel plates. Figure 12 illustrates the Serpent model of the ATR with two water compositions; white represents water held at a constant nominal density; only the density of the water in the purple-colored regions was changed for reactivity feedback calculations. The number densities of hydrogen and oxygen in this mixture were modified, using the values provided in Table 8. Moderator density reactivities were found to be non-linear, but not subject to the statistical variations seen in the Doppler reactivity calculations. 
Table 7: Global Doppler Reactivity

\begin{tabular}{ccccc}
\hline Power Split: & & $60 / 40$ & $70 \mathrm{MW}$ & $50 / 50$ \\
\hline $\begin{array}{c}\text { Average Fuel } \\
\text { Temperature } \\
\left({ }^{\circ} \mathrm{F}\right)\end{array}$ & $\begin{array}{c}\text { Serpent Fuel } \\
\text { Temperature } \\
(\mathrm{K})\end{array}$ & $\begin{array}{c}\text { Doppler } \\
\text { Reactivity }\end{array}$ & $\begin{array}{c}\text { Doppler } \\
\text { Reactivity }\end{array}$ & $\begin{array}{c}\text { Doppler } \\
\text { Reactivity }\end{array}$ \\
\hline 68 & 300.00 & $\$ 0.30$ & $\$ 0.28$ & $\$ 0.30$ \\
100 & 310.93 & $\$ 0.24$ & $\$ 0.23$ & $\$ 0.24$ \\
200 & 366.48 & $\$ 0.07$ & $\$ 0.06$ & $\$ 0.07$ \\
239 & 388.15 & $\$ 0.00$ & $\$ 0.00$ & $\$ 0.00$ \\
300 & 422.04 & $-\$ 0.11$ & $-\$ 0.10$ & $-\$ 0.11$ \\
400 & 477.59 & $-\$ 0.28$ & $-\$ 0.27$ & $-\$ 0.28$ \\
500 & 533.15 & $-\$ 0.46$ & $-\$ 0.43$ & $-\$ 0.46$ \\
600 & 588.71 & $-\$ 0.64$ & $-\$ 0.60$ & $-\$ 0.64$ \\
700 & 644.26 & $-\$ 0.81$ & $-\$ 0.76$ & $-\$ 0.81$ \\
\hline
\end{tabular}


Table 8: Moderator Density Reactivity

\begin{tabular}{|c|c|c|c|c|}
\hline Power Split: & & $60-40$ & $70 \mathrm{MW}$ & $50-50$ \\
\hline $\begin{array}{c}\text { Average Mod. } \\
\text { Density } \\
\left(\mathrm{lb}_{\mathrm{m}} / \mathrm{ft}^{3}\right)\end{array}$ & $\begin{array}{c}\text { Atomic } \\
\text { Number } \\
\text { Densities } \\
\text { (atoms/b-cm) }\end{array}$ & $\begin{array}{c}\text { Reactivity } \\
(\$)\end{array}$ & & \\
\hline$\sim 0$ & $\begin{array}{l}\text { H } 6.6387 \mathrm{E}-20 \\
\text { O } 3.3194 \mathrm{E}-20\end{array}$ & $-\$ 75.44$ & $-\$ 67.05$ & $-\$ 74.26$ \\
\hline 10 & $\begin{array}{l}\text { H } 1.0708 \mathrm{E}-2 \\
\text { O } 5.3539 \mathrm{E}-3\end{array}$ & $-\$ 53.16$ & $-\$ 47.47$ & $-\$ 52.60$ \\
\hline 20 & $\begin{array}{l}\text { H } 2.1415 \mathrm{E}-2 \\
\text { O } 1.0708 \mathrm{E}-2\end{array}$ & $-\$ 36.52$ & $-\$ 32.74$ & $-\$ 36.19$ \\
\hline 30 & $\begin{array}{l}\text { H } 3.2123 \mathrm{E}-2 \\
\text { O } 1.6062 \mathrm{E}-2\end{array}$ & $-\$ 23.84$ & $-\$ 21.62$ & $-\$ 23.79$ \\
\hline 40 & $\begin{array}{l}\text { H } 4.2830 \mathrm{E}-2 \\
\text { O } 2.1415 \mathrm{E}-2\end{array}$ & $-\$ 14.31$ & $-\$ 13.05$ & $-\$ 14.34$ \\
\hline 50 & $\begin{array}{l}\text { H } 5.3538 \mathrm{E}-2 \\
\text { О } 2.6769 \mathrm{E}-2\end{array}$ & $-\$ 6.88$ & $-\$ 6.27$ & $-\$ 6.85$ \\
\hline 60 & $\begin{array}{l}\text { H } 6.4245 \mathrm{E}-2 \\
\text { О } 3.2123 \mathrm{E}-2\end{array}$ & $-\$ 1.03$ & $-\$ 0.96$ & $-\$ 1.04$ \\
\hline 62.05 & $\begin{array}{l}\text { H } 6.6387 \mathrm{E}-2 \\
\text { O } 3.3194 \mathrm{E}-2\end{array}$ & $\$ 0.00$ & $\$ 0.00$ & $\$ 0.00$ \\
\hline
\end{tabular}




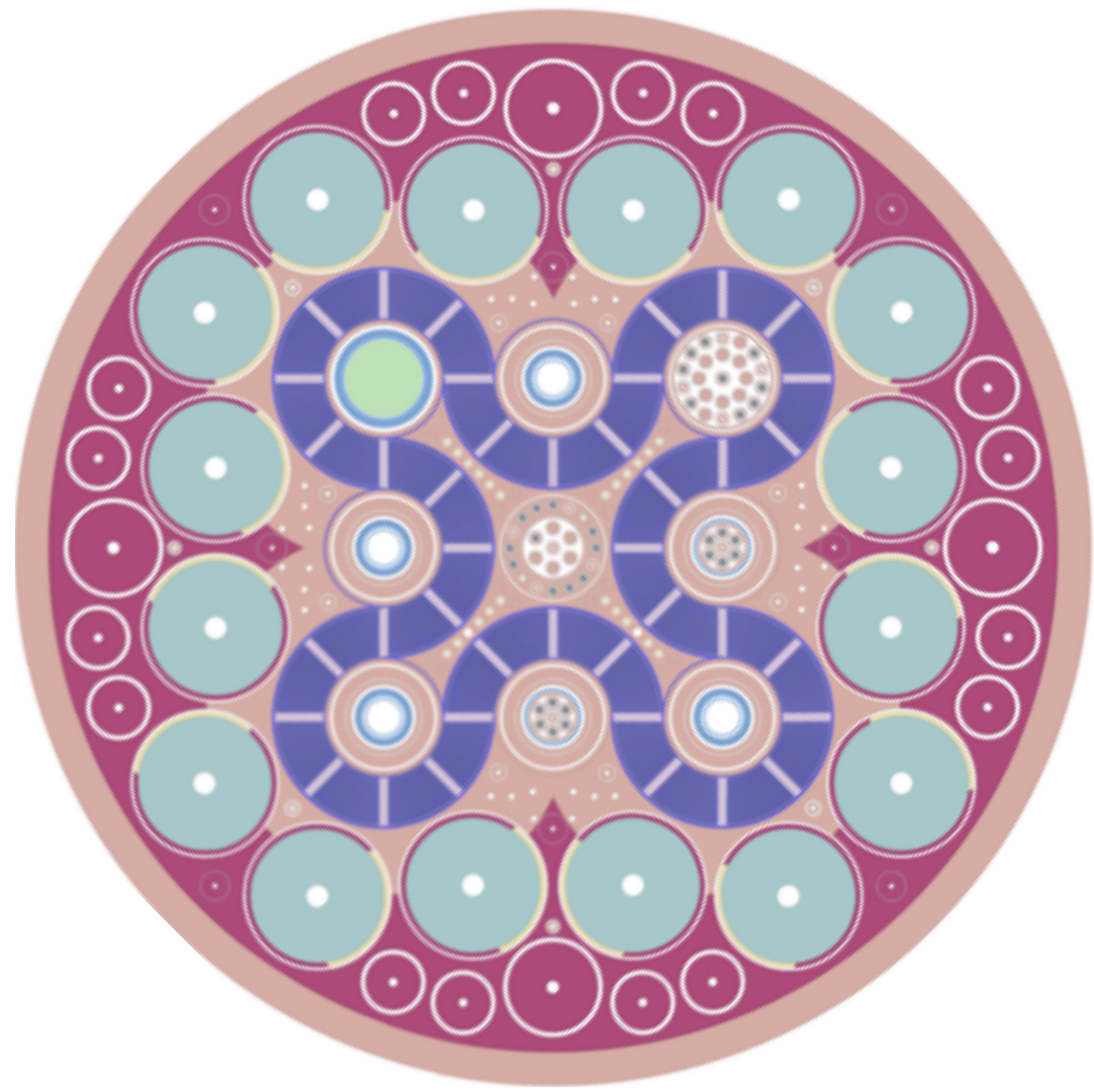

Figure 12: Moderator density model for ATR reactivity calculations. The purple region represents regions where moderator densities were perturbed. 


\section{SOURCE TERM ANALYSIS}

A number of additional analyses were performed to assess source terms from an LEU core relative to its HEU equivalent. Of particular interest were spent fuel activities and decay heats as well as ${ }^{16} \mathrm{~N}$ production rates in moderator and in ten N-16 flow tubes used for core power measurements. These calculations were performed to determine if changes would be required for fuel handling, storage, radiological release calculations and instrumentation.

\section{IX.A. Spent Fuel Activity}

Existing fuel handling hardware and procedures are based on doses expected from a spent HEU element. Reference [27] reports activities by nuclide and total activity following operation at $250 \mathrm{MW}$ for 60 days with an initally fresh core. Activities are reported at post-shutdown decay times of 4 hours, 8 hours, 1, 4, 7, 15, 30, 60, 90, 120, 150 days and one year. The reference calculations were performed using ORIGEN2 and of course were only for HEU fuel; the current calculations were performed using Serpent 2 and were performed for both HEU- and LEU-fueled cores. The Serpent calculations show that the LEU activity is somewhat higher for the first 30 days post shutdown, but slightly lower for the next 120-130 d, at which time the LEU source again becomes very slightly larger. Overall differences are small after approximately one week post-shutdown. Because of the introduction of significant ${ }^{238} \mathrm{U}$, LEU fuel produces higher initial activities due to the decay of higher actinides (e.g., ${ }^{239} \mathrm{~Np},{ }^{240} \mathrm{~Np}$ ). The increase in the beyond $150 \mathrm{~d}$ may be due to ${ }^{242} \mathrm{Cm}$, with its $163 \mathrm{~d}$ half life, although it could also be due to differences in the fission product inventories resulting from significant plutonium fission.

Figure 13 illustrates the results for both HEU and LEU fuels as calculated using Serpent 2, along with the results provided in Ref. [27]. Activities are for the full core (40 elements); however, for our purposes, differences in the relative source are the only data of interest. Note that the earlier ORIGEN2 results were calculated using a fixed cross section library and assumed three-group spectrum for a single average fuel specification, while the revised results are based on the core-averaged flux in each of the 19 fuel plates in each element, using a 3-D full core model. It is impressive to see how closely the earlier results match the revised HEU Serpent-based source. 


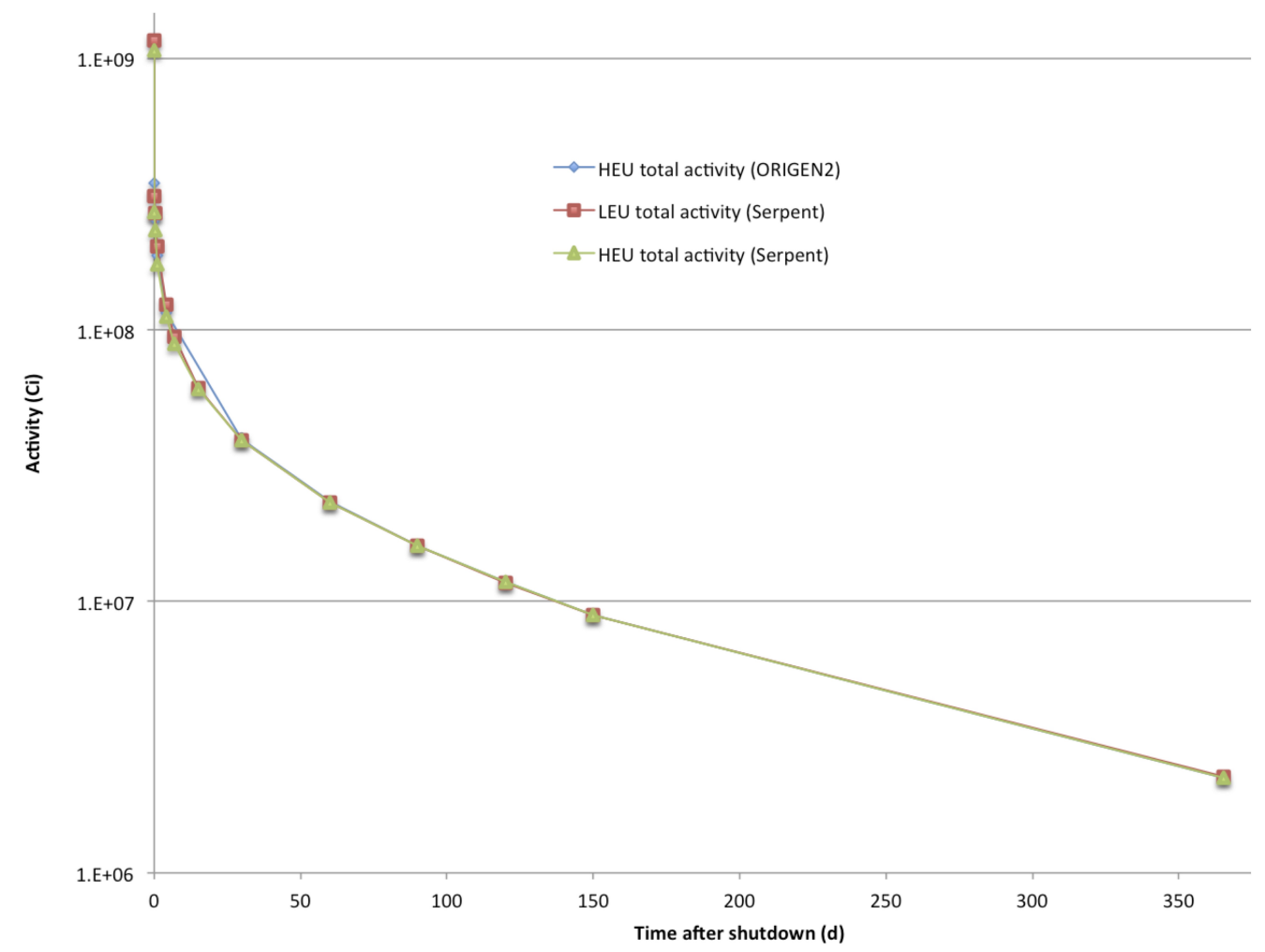

Figure 13: Spent Fuel Activity for HEU and LEU Fuels (Ci/Full Core)

\section{IX.B. Spent Fuel Decay Heat}

Post-shutdown decay heat sources were calculated in a similar manner. The total decay heat for the full core was calculated for all available isotopes, and summed into groups as actinides, fission products, and light elements. Light elements are comprised of non-fuel materials present in the fuel activated by irradiation: aluminum, boron, carbon and oxygen in HEU fuel and molybdenum in LEU fuel. Results for each group are provided in Tables 9 and 10. The last row of Table 10 provides the percentage change in the total decay heat for the two cores. As observed in the gamma source results, LEU has up to a $9 \%$ increase over HEU decay heat in days after shutdown, again likely due to the decay of higher actinides. By 30 days after shutdown decay heat differences are minor with HEU slightly higher. This changes over to LEU sometime after 150 days, but less that a $0.5 \%$ difference. 
Table 9: HEU Decay Heat Totals (Watts/Full Core)

\begin{tabular}{lllllllll}
\hline & Initial & $0.2 \mathrm{~d}$ & $1 \mathrm{~d}$ & $7 \mathrm{~d}$ & $30 \mathrm{~d}$ & $90 \mathrm{~d}$ & $150 \mathrm{~d}$ & $1 \mathrm{y}$ \\
\hline $\begin{array}{l}\text { Light } \\
\text { Elements }\end{array}$ & $1.89 \mathrm{E}-2$ & $3.58 \mathrm{E}-3$ & $2.41 \mathrm{E}-3$ & $5.50 \mathrm{E}-4$ & $9.15 \mathrm{E}-5$ & $8.97 \mathrm{E}-5$ & $8.89 \mathrm{E}-5$ & $8.60 \mathrm{E}-5$ \\
Actinides & $1.69 \mathrm{E}+4$ & $1.08 \mathrm{E}+4$ & $9.07 \mathrm{E}+3$ & $3.09 \mathrm{E}+3$ & $2.23 \mathrm{E}+2$ & $5.29 \mathrm{E}+0$ & $4.79 \mathrm{E}+0$ & $4.70 \mathrm{E}+0$ \\
$\begin{array}{l}\text { Fission } \\
\begin{array}{l}\text { Products } \\
\text { Total }\end{array}\end{array}$ & $1.40 \mathrm{E}+7$ & $1.60 \mathrm{E}+6$ & $8.26 \mathrm{E}+5$ & $4.03 \mathrm{E}+5$ & $1.64 \mathrm{E}+5$ & $6.13 \mathrm{E}+4$ & $3.53 \mathrm{E}+4$ & $8.74 \mathrm{E}+3$ \\
\hline
\end{tabular}

Table 10: LEU Decay Heat Totals (Watts/Full Core)

\begin{tabular}{lllllllll}
\hline & Initial & $0.2 \mathrm{~d}$ & $1 \mathrm{~d}$ & $7 \mathrm{~d}$ & $30 \mathrm{~d}$ & $90 \mathrm{~d}$ & $150 \mathrm{~d}$ & $1 \mathrm{y}$ \\
\hline $\begin{array}{l}\text { Light } \\
\begin{array}{l}\text { Elements } \\
\text { Actinides }\end{array}\end{array}$ & $4.26 \mathrm{E}-2$ & $7.80 \mathrm{E}-3$ & $5.18 \mathrm{E}-3$ & $1.02 \mathrm{E}-3$ & $2.11 \mathrm{E}-6$ & $6.87 \mathrm{E}-9$ & $6.81 \mathrm{E}-9$ & $6.58 \mathrm{E}-9$ \\
& $2.06 \mathrm{E}+5$ & $9.54 \mathrm{E}+4$ & $7.50 \mathrm{E}+4$ & $1.42 \mathrm{E}+4$ & $2.19 \mathrm{E}+2$ & $1.08 \mathrm{E}+1$ & $1.00 \mathrm{E}+1$ & $9.51 \mathrm{E}+0$ \\
$\begin{array}{l}\text { Fission } \\
\text { Products }\end{array}$ & $1.44 \mathrm{E}+7$ & $1.62 \mathrm{E}+6$ & $8.34 \mathrm{E}+5$ & $4.03 \mathrm{E}+5$ & $1.63 \mathrm{E}+5$ & $6.09 \mathrm{E}+4$ & $3.50 \mathrm{E}+4$ & $8.76 \mathrm{E}+3$ \\
Total & $1.46 \mathrm{E}+7$ & $1.72 \mathrm{E}+6$ & $9.08 \mathrm{E}+5$ & $4.17 \mathrm{E}+5$ & $1.63 \mathrm{E}+5$ & $6.09 \mathrm{E}+4$ & $3.50 \mathrm{E}+4$ & $8.77 \mathrm{E}+3$ \\
$\begin{array}{l}\text { Change } \\
\text { from HEU }\end{array}$ & $4.29 \%$ & $6.83 \%$ & $8.74 \%$ & $2.71 \%$ & $-0.61 \%$ & $-0.67 \%$ & $-0.85 \%$ & $0.34 \%$ \\
\hline
\end{tabular}




\section{IX.C. ${ }^{16} N$ Production Rate in Coolant}

During reactor operation, ${ }^{16} \mathrm{~N}$ is produced when ${ }^{16} \mathrm{O}$ captures a neutron, ${ }^{16} \mathrm{O}(\mathrm{n}, \mathrm{p}){ }^{16} \mathrm{~N} .{ }^{16} \mathrm{~N}$ beta decays to a high-energy state of ${ }^{16} \mathrm{O}$ with a $7.1 \mathrm{~s}$ half life, followed immediately by the emission of a 6.1 or $7.1 \mathrm{MeV}$ gamma to return to the ground state. In the event of a loss of coolant, water from the core is radioactive for minutes after leaving the core. To determine the

${ }^{16} \mathrm{~N}$ source, the production rate for the nuclide is needed. Hence, the flux in the core is needed. Because the ${ }^{16} \mathrm{O}(\mathrm{n}, \mathrm{p}){ }^{16} \mathrm{~N}$ reaction has a high energy (10 $\mathrm{MeV}$ ) threshold, essentially all ${ }^{16} \mathrm{~N}$ in produced in the 20 coolant channels within each fuel element. Hence, calculations were performed to estimate the flux and ${ }^{16} \mathrm{~N}$ production rate for the coolant located only within those flow channels, for both HEU and LEU core models. Figure 14 shows the calculated spectra for both fuel type for the ATR operating at $105 \mathrm{MW}$. The loss of neutrons during the slowing down process is clear and is expected due to ${ }^{238} \mathrm{U}$ capture. However, only the fluxes above $10 \mathrm{MeV}$ are important. While the highest energies look identical, differences are being hidden by the scale of the graph. Figure 15 shows a close-up view of fluxes above $10 \mathrm{MeV}$. Here it is very clear that the coolant flux in the LEU ELF-fueled core is slightly lower than that of the HEU fuel. This is believed to be due to the presence of significantly increased masses of ${ }^{238} \mathrm{U}$ and a somewhat increased mass of ${ }^{235} \mathrm{U}$ resulting in more uranium scattering; as a heavy nuclide small energy losses will be seen in such collisions. These plots indicate that ${ }^{16} \mathrm{~N}$ production will be slightly lower $(\sim 6 \%)$ for coolant flow adjacent to LEU fuel. Note that there is a statistical error associated with the plots, but the models were converged such that the high energy fluxes were converged to less that $1 \%$ uncertainty. Hence, the magnitude of the reduced ${ }^{16} \mathrm{~N}$ production has a significant uncertainty.

\section{IX.D. ${ }^{16} N$ Production Rate in N-16 Flow Tubes}

The decay of ${ }^{16} \mathrm{~N}$ provides a means for estimating the local core power, which will be proportional to the ${ }^{16} \mathrm{~N}$ decay rate in the coolant. In fact, ATR uses special flow tubes placed around the core, with gamma detectors at the outlet of each to determine lobe and core powers. ATR has a total of 10 such flow tubes and detector systems. The concern with these systems was that the activity of ${ }^{16} \mathrm{~N}$ would change significantly, requiring modification or replacement of the gamma detectors. The results of the work described in Sect. IX.C indicate that activities will not change significantly; these calculations were performed for completeness. 


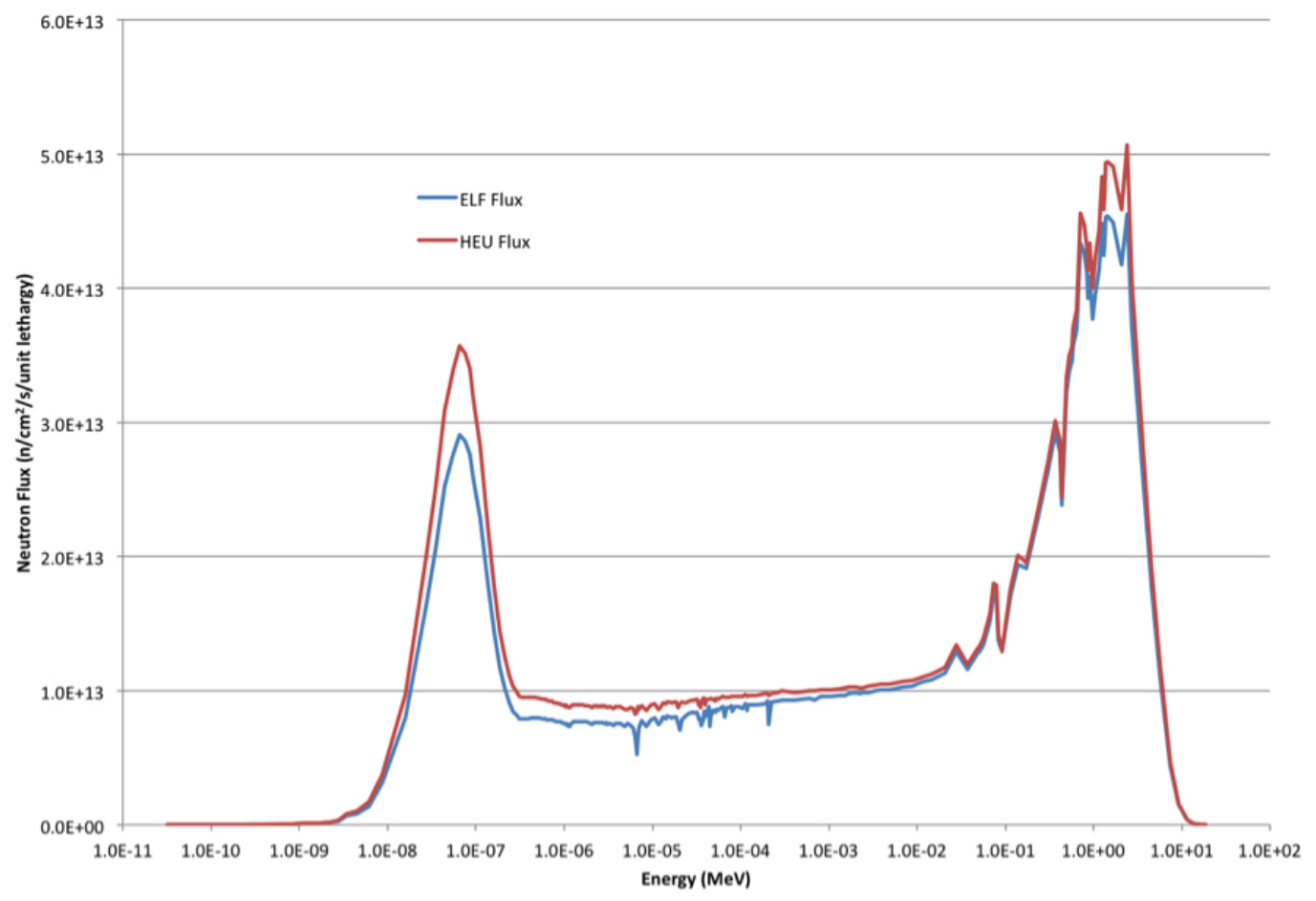

Figure 14: Average Neutron Spectra in ATR Coolant Channels for LEU and HEU fueled cores

The N-16 tubes actually consist of two cylindrical tubes: an inner cylinder within an outer cylinder, allowing up and down flow in one location. With one exception (described below) water flows up the outer tube and returns down the inner tube, such that the water goes past the full height of the core twice. N-16 tubes have locations outside each of the four lobes at NE, NW, SW and SE positions, located between adjacent OSCCs, at N, S, E and W locations outside the OSCCs, and two in the center flux trap in positions H3 and H16. Unlike the other 9 locations, the flow in $\mathrm{H} 3$ only flows up to the axial mid-plane in the outer tube before reversing and traveling down the inner tube. Thus, data from the $\mathrm{H} 3$ and $\mathrm{H} 16$ tubes can be used to determine the power in top and bottom halves of the core.

Because of the relatively small volume of water in the N-16 tubes, calculations were performed with $2 \times 10^{10}$ neutron histories to reduce statistical uncertainties. Results of these calculations, with associated uncertainties, are provided in Table 11. For the most part, LEU shows slightly lower ${ }^{16} \mathrm{~N}$ 


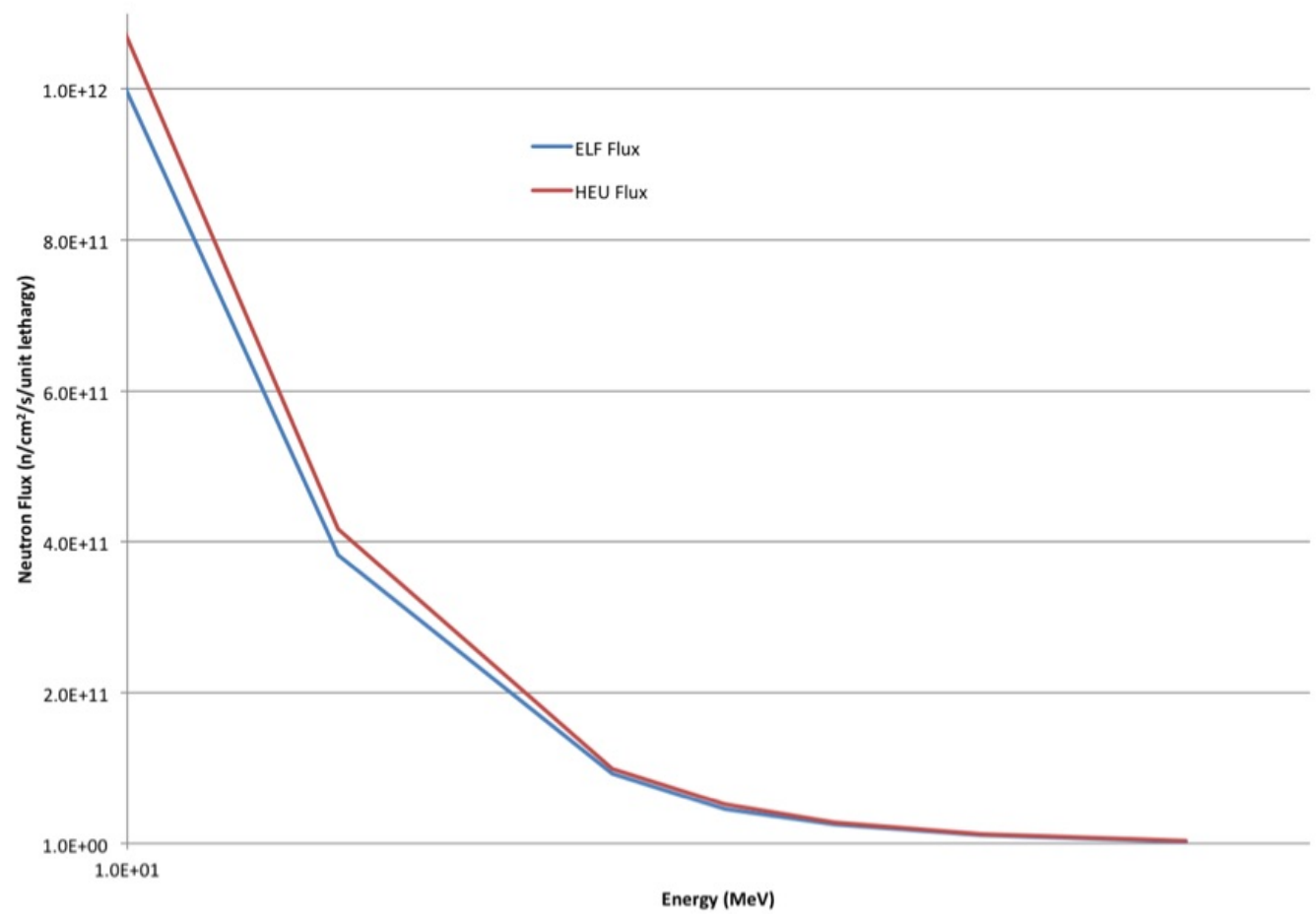

Figure 15: Average Neutron Spectra in ATR Coolant Channels for LEU and HEU fueled cores

production in the than HEU in N-16 positions. The NE location shows a very small positive difference, while the remaining inter-cardinal fuel positions show a negative difference. The uncertainty for these positions is on the order of $4 \%$ or less, so the positive difference for the NE position is within the uncertainty for the calculation. For the four cardinal directions, $\mathrm{LEU}{ }^{16} \mathrm{~N}$ production is less than that of the HEU fuel; however, because these N-16 positions are farther out in the care and behind OSCCs, the uncertainty of these tallies is significantly larger, on the order of $12-16 \%$. This indicates that the sign $(+/-)$ of the values is likely, but that there is considerable uncertainty in the magnitude hence the larger variations. Interestingly, the two central positions $\mathrm{H} 3$ and $\mathrm{H} 16$ show a statistically significant positive change for LEU vs HEU. The reason for this behavior is unknown and further study may be warranted. 
Table 11: ${ }^{16} \mathrm{~N}$ Production Rates in the Ten ATR N-16 Positions

\begin{tabular}{|c|c|c|c|}
\hline $\begin{array}{l}\text { N-16 } \\
\text { Position }\end{array}$ & $\begin{array}{l}\text { LEU N-16 } \\
\text { Production Rate, } \\
\text { atoms } / \mathrm{cm}^{3} / \mathrm{sec} \text {. }\end{array}$ & $\begin{array}{l}\text { HEU N-16 } \\
\text { Production Rate, } \\
\text { atoms } / \mathrm{cm}^{3} / \mathrm{sec} \text {. }\end{array}$ & 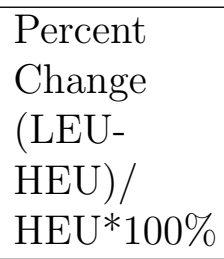 \\
\hline $\mathrm{NE}$ & $1.01 \mathrm{E}+11+/-0.047 \%$ & $1.01 \mathrm{E}+11+/-0.047 \%$ & $0.60 \%$ \\
\hline NW & $9.91 \mathrm{E}+10+/-0.046 \%$ & $1.06 \mathrm{E}+11+/-0.045 \%$ & $-6.66 \%$ \\
\hline SW & $1.31 \mathrm{E}+11+/-0.040 \%$ & $1.36 \mathrm{E}+11+/-0.040 \%$ & $-3.27 \%$ \\
\hline $\mathrm{SE}$ & $1.40 \mathrm{E}+11+/-0.040 \%$ & $1.50 \mathrm{E}+11+/-0.038 \%$ & $-6.95 \%$ \\
\hline $\mathrm{N}$ & $6.79 \mathrm{E}+09+/-0.16 \%$ & $8.00 \mathrm{E}+09+/-0.15 \%$ & $-15.12 \%$ \\
\hline W & $1.09 \mathrm{E}+10+/-0.14 \%$ & $1.14 \mathrm{E}+10+/-0.14 \%$ & $-4.24 \%$ \\
\hline S & $1.46 \mathrm{E}+10+/-0.13 \%$ & $1.54 \mathrm{E}+10+/-0.12 \%$ & $-5.53 \%$ \\
\hline $\mathrm{E}$ & $8.50 \mathrm{E}+09+/-0.16 \%$ & $1.01 \mathrm{E}+10+/-0.14 \%$ & $-16.21 \%$ \\
\hline H3 & $1.44 \mathrm{E}+11+/-0.039 \%$ & $1.01 \mathrm{E}+11+/-0.047 \%$ & $43.49 \%$ \\
\hline H16 & $2.99 \mathrm{E}+11+/-0.027 \%$ & $1.06 \mathrm{E}+11+/-0.045 \%$ & $181.43 \%$ \\
\hline
\end{tabular}




\section{CONCLUDING REMARKS}

This paper has provided a summary of the approaches used to generate data for RELAP5 calculations in support of ATR safety analyses for ELF Mk 1A LEU fuel. Serpent-based Monte Carlo calculations have been performed to provide heat source terms for RELAP5 3D core thermal-hydraulic calculations and detailed SINDA thermal-hydraulic calculations for limiting hot-channel locations, for a variety of postulated accident scenarios.

Following several years of preliminary scoping design calculations, the initial ELF fuel element design [13] was selected to proceed into the conceptual design phase for an LEU fuel element for ATR. This was the result of a traditional engineering selection process involving many design variations. Early in the LEU conversion design process, a number of pre-conceptual designs were developed and assessed using reactor physics evaluations based on performance requirements provided by DOE/NNSA's Naval Reactor Office (NR) and showed essentially the same level of performance. LEU fuel design behavior appears to be more a function of the spectrum within the LEU fuel than the specific attributes of the different LEU designs. Thus, that work in and of itself was not used to disqualify any of the pre-conceptual designs in moving into the conceptual design phase. Hence, fuel concepts were evaluated further using thermal-hydraulic calculations to assess safety limits performance. Again, these analyses were insufficient to determine the best design to advance to conceptual design analysis. Ultimately, materials performance requirements and the simplicity and cost of fabrication were used to select the ELF design as the conceptual design choice.

Scoping physics calculations were used to further refine the ELF concept for the most challenging safety limits, resulting in the ELF Mk $1 \mathrm{~A}$ and $\mathrm{Mk}$ 1B design specifications. Evaluation of the ELF Mk 1A and ELF Mk 1B designs shows that the ELF design for the most part meets the spirit of those requirements [28]. LEU is a highly effective gamma shield relative to HEU in ATR, so gamma fluxes in experimental positions will be reduced in any LEU design. However, gamma fluxes above $1 \mathrm{MeV}$ are not significantly attenuated by an LEU fuel. In addition, other research has been initiated to determine if the currently limiting lobe power of $60 \mathrm{MW}$ can be increased to $70 \mathrm{MW}$. This would allow the LEU design to meet all of the initial performance requirements.

Analyses are also ongoing regarding the impacts of uncertainty in fuel meat thickness [23]. It was determined that there exist plate-to-plate inter- 
actions that can contribute to higher heat fluxes when neighboring plates have certain combinations of thicknesses. Therefore, a statistical approach is being applied in order to determine worst-case impacts of this uncertainty.

This work represents a small segment of the entire ATR LEU conversion process. These analyses support, in part, generation of safety basis analysis and documentation demonstrating that ATR and ATRC can operate safely and to a high probabily survive postulated safety-basis accidents, in support of the conclusion that health and safety of the public will continue to be protected after conversion. It is important to note that the results in this report are preliminary and as the design continues to develop, improved results may become available. It is possible that the fabrication process will encounter changes that will require consideration by the design team. This will be an iterative process and it is understood that revisions or additions to this analysis may be necessary in the future. In addition, irradiation of prototypic designs and determination of performance limits for U-10Mo fuel are ongoing, with longer-term plans for lead test assemblies based on the ELF design. Fuel performance data will be used along with the results of this work in setting final performance limits and in validation of the calculational approach described here for application to ELF. 


\section{Bibliography}

[1] J. A. Ulrich and S. Robertson, ATR National Scientific User Facility 2013 Annual Report, Tech. Rep. INL/EXT-14-32057, Idaho National Laboratory, Idaho Falls, ID (June 2013).

[2] National Nuclear Security Administration, GTRI's Convert Program: Minimizing the Use of Highly Enriched Uranium, http://www.nnsa.energy.gov/mediaroom/factsheets/gtri-convert/.

[3] National Academies of Sciences, Engineering, and Medicine, Reducing the Use of Highly Enriched Uranium in Civilian Research Reactors, The National Academies Press, Washington, DC, 2013. doi:10.17226/21818.

[4] U. S. Department of Energy, Global Threat Reduction Initiative (GTRI) - PNNL GTRI Convert Program Program Management Plan, Tech. Rep. PNNL-22443, Pacific Northwest National Laboratory (Apr 2013).

[5] IAEA, Development status of metallic, dispersion and non-oxide advanced and alternative fuels for power and research reactors, Tech. Rep. IAEA-TECDOC-1374; (ISBN:92-0-110303-4), International Atomic Energy Agency, Vienna, Austria (September 2003).

[6] M. K. Meyer, J. Gan, J. F. Jue, D. D. Keiser, E. Perez, A. Robinson, D. M. Wachs, N. Woolstenhulme, G. L. Hofman, and Y. S. Kim, Irradiation Performance of U-Mo Monolithic Fuel (2014).

[7] A. B. Robinson, Irradiation Performance of U-Mo Alloy Based "Monolithic" Plate-Type Fuel-Design Selection, https://inldigitallibrary.inl.gov/sti/4363871.pdf (2009).

[8] D. J. Senor and D. Burkes, Fuel fabrication capability research and development plan, Tech. Rep. PNNL-22528, Pacific Northwest National Laboratory, Richland, Washington 99352 (June 2013).

[9] G. S. Chang, R. G. Ambrosek and M. A. Lillo, Advanced Test Reactor LEU Fuel Conversion Feasibility Study (2006 Annual Report), Tech. Rep. INL/EXT-06-11887, Idaho National Laboratory (Dec 2006).

[10] Chang, G. S., ATR LEU Fuel and Burnable Absorber Neutronics Performance Optimization by Fuel Meat Thickness Variation, in: RERTR2007 - International Meeting on Reduced Enrichment for Research and 
Test Reactors, no. INL/CON-07-12949, RERTR, Prague, Czech Republic, 2007.

[11] Chang, G. S., ATR LEU Monolithic Foil-Type Fuel with Integral Cladding Burnable Absorber Design - Neutronics Performance Evaluation, in: RERTR 2011 - 33rd International Meeting on Reduced Enrichment for Research and Test Reactors, RERTR, Santiago, Chile, 2011.

[12] DeHart, M. D., Skerjanc, W. F., and Morrell, S. R., Analysis of the Reactor Physics of Low-Enrichment Fuel for the INL Advanced Test Reactor in support of RERTR, in: Proc. ANS Annual Meeting, ANS, Chicago, IL, 2012.

[13] M. D. DeHart, M. A. Pope, D. W. Nigg, R. K. Jamison and S. R. Morrell, Fuel element design and analysis for advanced test reactor conversion to leu fuel, Vol. 109, American Nuclear Society, Washington, DC, 2013.

[14] J. Leppänen, Serpent progress report 2011, Tech. Rep. VTT-R-05444-12, VTT Technical Research Centre, Espoo, Finland (2012).

[15] VTT Technical Research Centre of Finland, Serpent 1.1.7: Continuous Energy Monte Carlo Reactor Physics Burnup Calculation Code, http://www-rsicc.ornl.gov/codes/ccc/ccc7/ccc-757.html.

[16] The X-5 Monte Carlo Team, MCNP - A General, Monte Carlo N-Particle Transport Code (Version 5), Tech. Rep. Report LA-UR-03-1987, Los Alamos National Laboratory (2003).

[17] Kim, S. S. and Schnitzler, B.G., Advanced Test Reactor: Serpentine Arrangement of Highly Enriched Water-Moderated Uranium-Aluminide Fuel Plates Reflected by Beryllium, Tech. Rep. NEA/NSC/DOC/(95)03/II, Volume II, HEU-MET-THERM-022, Nuclear Energy Agency of the Organization for Economic Cooperation and Development (Sep 2005).

[18] I. N. Laboratory (Ed.), Verification and Validation of Corrected Versions of RELAP5 for ATR Reactivity Analyses, no. INL/CON-08-14843, 2008 RELAP5 International Users Group Meeting, Idaho Falls, ID, 2008. 
[19] S. T. Polkinghorne, Validation of the ATR-SINDA Fuel Plate Model Using Advanced Test Reactor Startup Data, Nucl. Technol. 108 (3) (1994) 395-412.

[20] K. H. Liebelt, Users manual for sinda hydraulic/statistical model of the hot stripe in an atr fuel plate., Tech. Rep. PG-T-96-006, Idaho National Laboratory (November 1996).

[21] S . S . Kim, J . A . McClure, PDQ Reactor Physics Analysis for the ATR-FSAR Upgrade, Tech. Rep. PG-T-92-003 Rev. 1, Idaho National Laboratory (September 1993).

[22] A. P. Cochran Letter to A. J. Bieniawski, Naval Reactors Functional Requirements for the Advanced Test Reactor, NR:RM:APCochran S\#0804461 (Dec 11 2008).

[23] M. A. Pope, M. D. DeHart, D. W. Nigg, R. K. Jamison, S. R. Morrell, Fuel Element Design and Analysis for Advanced Test Reactor Conversion to Low Enriched Uranium Fuel, in: Transactions of RRFM 2014 European Research Reactor Conference, European Nuclear Society, Ljubljana, Slovenian, 2014.

[24] J. W. Nielsen, As-Run Physics Analysis for the UCSB-1 Experiment in the Advanced Test Reactor, Tech. Rep. INL/EXT-15-34225, Idaho National Laboratory, Idaho Falls, Idaho (September 2015).

[25] D. P. Griesheimer, D. F. Gill, B. R. Nease, T. M. Sutton, M. H. Stedry, P. S. Dobreff, D. C. Carpenter, T. H. Trumbull, E. Caro, H. Joo, and D. L. Millman, MC21 v.6.0 - A continuous-energy Monte Carlo particle transport code with integrated reactor feedback capabilities (2015).

[26] W. R. Cadwell, PDQ-7 Reference Manual, Tech. Rep. WAPD-TM678, Bettis Atomic Power Laboratory, Pittsburg, Pennsylvania (January 1967).

[27] M. L. Carboneau, ORIGEN2 Calculated Core Inventories and Photon Source Term for the ATR SAR, Tech. Rep. TRA-ATR-784, EG\&G Idaho, Inc., Idaho Falls, ID (May 1993).

[28] M. A. Pope, M. D. DeHart, S. R. Morrell, R. K. Jamison, E. C. Nef and D. W. Nigg, Enhanced Low-Enriched Uranium Fuel Element for the 
Advanced Test Reactor, in: RERTR 2014 - 35th International Meeting on Reduced Enrichment for Research and Test Reactors, International Atomic Energy Agency, IAEA Vienna International Center, Vienna, Austria, 2014. 